\title{
BIM semantic-enrichment for built heritage representation
}

\author{
Davide Simeone $^{\mathrm{a}, *}$, Stefano Cursi ${ }^{\mathrm{a}}$, Marta Acierno ${ }^{\mathrm{b}}$ \\ ${ }^{a}$ Department of Civil, Construction and Environmental Engineering, Sapienza University of Rome, Via Eudossiana, 18, 00184 Rome, Italy \\ ${ }^{\mathrm{b}}$ Department of History, Representation and Conservation of Architecture, Sapienza University of Rome, Piazza Borghese, 9, 00186 Rome, Italy
}

A R T I C L E I N F O

\section{Keywords:}

BIM

Knowledge management

Built Heritage

Semantic-enrichment

Information ontologies

\begin{abstract}
A B S T R A C T
In the built heritage context, BIM has shown difficulties in representing and managing the large and complex knowledge related to non-geometrical aspects of the heritage. Within this scope, this paper focuses on a domainspecific semantic-enrichment of BIM methodology, aimed at fulfilling semantic representation requirements of built heritage through Semantic Web technologies. To develop this semantic-enriched BIM approach, this research relies on the integration of a BIM environment with a knowledge base created through information ontologies. The result is knowledge base system - and a prototypal platform - that enhances semantic representation capabilities of BIM application to architectural heritage processes. It solves the issue of knowledge formalization in cultural heritage informative models, favouring a deeper comprehension and interpretation of all the building aspects. Its open structure allows future research to customize, scale and adapt the knowledge base different typologies of artefacts and heritage activities.
\end{abstract}

\section{Introduction}

\subsection{Built heritage information modelling}

Since its introduction, BIM has produced sensible advantages in those contexts where the AEC industry mainly gears to new construction, while the actual impact in the field of existing buildings intervention - and in particular to heritage buildings - is still limited. Intervening on built heritage is a highly complex task where, in addition to traditional AEC projects issues, new elements make more difficult to reach effective and high-quality design results. Such an issue is affected by the amount and the quality of information related to the built heritage that is shared by the different actors. Recently, some research has shown the potentialities of the application of a BIM-oriented approach to these processes but some issues have progressively emerged. In particular, the research problem addressed in this research is that, at present, built heritage informative models remains poor in terms of semantics and a large area knowledge area, related to relevant features of the artefact, such as its history or its modifications during the time, are not adequately represented. Although some research has focused on how to add knowledge to built heritage models to include some specific aspects, a general framework for their semantic-enrichment, specifically finalized to support investigation and conservation processes, is still missing. The two main consequences, that deeply affect conservation activities, are:
1) Built heritage information models do not usually provide an adequate representation that includes the relevant semantics also considering specificness and uniqueness of artefacts;

2) Without a general framework for semantics representation and management, the conservation process cannot fully act as an integrated system of activities that gather and share knowledge about the artefact and the intervention.

The main research question that rises from these elements regards the structure, the components and the behaviour of a general model that, relying on the integration of BIM and Semantic Web technologies, can assure a comprehensive and flexible formalization and management of the large amount of multidisciplinary knowledge elaborated in conservation processes, therefore taking into account both investigation and conservation planning. Going deeper, the questions related to the development of this semantic-enriched BIM model for built heritage are: 1) how to enhance representation semantic level by providing information with its necessary interpretation context; 2) how to extend the representation domain including all the knowledge necessary for artefact comprehension but not directly includable in its physical components (such as history or context information); 3) how to formalize this knowledge in a computable way, making it inferable through rules and algorithms.

To answer to these questions, the paper has been organised as to follow: an analysis of current BIM application to built heritage (2.1), an

\footnotetext{
* Corresponding author.

E-mail addresses: davide.simeone@uniroma1.it (D. Simeone), stefano.cursi@uniroma1.it (S. Cursi), marta.acierno@uniroma1.it (M. Acierno).
} 
introduction to the topic of BIM semantic-enrichment in AEC (2.2) and a summary of the state of the art of ontologies application within the cultural heritage scope (2.3). Further on, Section 3 presents the study case upon which the proposed model has been developed and Section 4 focusses on the research methodology and results, describing the methodology and the conceptual structure of the model (4.1), as well as its different components: the BIM environment (4.2.1), the knowledge base (4.2.2), the SWRL reasoning component (4.2.3) and the BIM Semantic Bridge (4.2.4).

\section{Theoretical frame}

\subsection{BIM for built heritage}

Cultural heritage conservation project relies on two linked aspects, the identification of historical and architectural values of the building and the evaluation of its physical consistency, both addressing conservation decisions. While the physical consistency investigation could be carried on as an analytic and scientific process, the values assessment defines the building in terms of authenticity and identity ([48]: principles for conservation and restoration of built heritage, 2000), rises from the critical comprehension of the artefact.

The information necessary for this full comprehension is diversified, interrelated and, often, its sharing is not sufficient for real comprehension and collaboration [34] [35] but it is necessary to provide information with its interpretative context.

In the AEC industry, some research has aimed at enlarging BIM application domain in order to include existing buildings [49] [3] and built heritage artefacts [46], mainly focusing on establishing databases of past and present conditions of the building rather than conceiving BIM as a hub for supporting integrated documentation of heritage artefacts. In analogy with the spread of BIM in the AEC field, the variety of BIM-oriented approaches and case studies have been addressed to different heritage activities such as investigation, conservation, documentation, design and reuse, virtual reconstruction, management, and communication. Circumscribing this vast literature to the research scope, two brief categories of BIM approaches can be defined to better understand the current state of the art in such a context: the Historical Building Information Modelling (HBIM) and the Reality-based BIM for heritage. The discriminating criterion lies in the process of generation of the informative model of the built heritage artefact, taking into account if such a model is generated by relying on abstract, literaturebased parametric families or on the direct generation of ad hoc families and instances derived from data and information directly collected through investigation activities on the artefact.

The HBIM, firstly introduced by Murphy et al. [40] and Dore and Murphy [21], is based on libraries of parametric BIM objects for the heritage constructed through Geometric Descriptive Language (GDL) and used as a connection between the survey data collection and the informative BIM model [10]. As an example, Oreni et al. [42] relied on the HBIM approach for the conservation project of the Basilica of St. Maria of Collemaggio (damaged in 2009 by the Aquila earthquake) for managing the stages of simulation of structural behaviour, analysis, economic evaluation of the project, and restoration of the building. These experiences are relevant to show the capabilities of BIM schema to describe the heritage artefact in terms of its physical components. Nevertheless, as a limit of this approach, the use of libraries of parametric elements derived from theoretical architectural history essays and books clashes with the uniqueness and built heritage artefacts, deeply correlated to its history and historical events. In this perspective, the use of abstract families causes the loss of a large amount of relevant information and provides a misleading or inaccurate representation. In addition, the parametric rules behind the development of those families cannot correlate to specific contexts and periods of the heritage artefact, and the use of simplified geometries cuts off all the information regarding the current state of the construction elements such as missing pieces, damaged parts or reused elements.

With the advent of the integration of laser scanning data in BIM environments, some research has worked on the application of realitybased BIM methodologies to overcome the representational limits of HBIM. Some approaches are focused on the material and historical investigation of the building, through the survey, the definition of the type and the state of conservation of the materials [24]. Others are oriented to the development of a more accurate parametric model related an existing building starting from the data of a topographic and a laser scanner survey and from an archival documents research [17], and even to automatic 3D building modelling from remote sensing technologies [1]. These research efforts provided a great improvement in terms of physical accuracy of representation and, as a consequence, of geometrical comprehension of the artefact. In this approach, the geometries of the different components of the artefact are scanned, imported in the BIM environment and manually assigned to macro-sets of families. Although the accuracy of geometrical representation is preserved, some issues arose in terms of representation and manageability of non-geometric information and of the provision of knowledge not specifically related to scanned surfaces.

From the analysis of the described approaches, we can affirm that the key issue of semantics representation is still not adequately addressed and, while the quality of geometrical representation is progressively increasing in research, a few works (mentioned in the following section) are focusing on how to improve knowledge representation and management in built heritage. This representation gap has to be necessarily filled up as, within cultural heritage conservation process, the geometrical representation cannot be conceived as a step apart from critical and historical knowledge.

\subsection{Semantic-enriched BIM}

Since the introduction of BIM and IFC in the AEC field, the topic of semantic-enrichment has been investigated in order to enhance quality and level of non-geometrical information associated with tri-dimensional representations, often through implementation and evolution of IFC schemas [36] [22] [33] [7].

More recently, the introduction of Linked Data approach and of Semantic Web technologies has opened new possibilities in BIM semantic-enrichment. As described by Pauwels et al. [44] the analogy between construction industry representation schemes (i.e. IFC) and semantic network description logics (RDF and OWL), has favoured the implementation of information ontologies in the AEC industry, usually combined with Express rules. In 2005, Beetz et al. [6] introduced an embryonic version of the future IfCOWL ontology that has to be considered the first step in extending AEC structured information sets to the world of semantic ontologies. These works - representative of a larger research area - demonstrated the ability of semantic networks and informative ontologies to enhance project documentation and data accessibility. An open problem is, nevertheless, the definition of a reference classification schema sufficiently wide and open to support ontologies formalization and data exchange.

Jeong [32] investigated the use of ontologies for semantics sharing in multidisciplinary design. In the same period, Carrara et al. [14] proposed ontologies as a way to move towards knowledge-based models to improve collaboration in AEC processes. In these two cases, the attention is more on knowledge exchange and provision of information with its interpretative context - an aspect relevant for built heritage field - while no comprehensive knowledge base structures are defined. The combination of BIM and Semantic Web has progressively shown all its potentials in enhancing the level of semantic representation in the AEC. Nevertheless, those efforts are mainly oriented to new construction design, while only a few attempts have been made in translating these approaches and methodologies to built heritage processes, where relevance and amount of necessary semantics are even bigger. In the HBIM approach, this task is partially carried out through 
City GML, a methodology derived from Geographical Information Systems area and used to associate non-geometrical data to specific points belonging to physical components of the building [21]. While this approach is quite efficient when integrated with point-based survey techniques, limits emerge when applied to component-based representations such as building information models. In addition, this methodology shows difficulties in representing all the information not directly associable to points in space, and this is extremely counterproductive in built heritage field since it leaves a large part of relevant knowledge out from the informative models. Similarly to the new building design area, some research has focused on the integration of Semantic Web technologies and BIM to enrich representation of heritage artefacts. Pauwels et al. [45] [43] and Di Mascio et al. [18] relied on the integration of ifcOWL (connected with other heritage-specific ontologies) and game engines to provide an informative tridimensional representation of heritage architecture. These experiments, that we consider relevant references for our research, demonstrated the potential of extending the BIM representation to include knowledge bases specifically designed for some aspects of built heritage. It is also clear the lack of a more general framework for inclusion and management of the whole system of information necessary for a full documentation of the artefact. Other projects, such as DURAARK - Durable Architectural Knowledge - project [19] [5], aimed at providing tools and methods for the Long-Term Preservation (LTP) of architectural artefact knowledge through the development of BIM models, also derived from point clouds, and of RDF datasets concerning architectural data with its internal and external relations. In this case, the research provided an insight of the potential of Semantic Web technologies and BIM to conserve and document the artefact during the time, providing a reference dataset to support preservation activities.

All these experiences, however, have highlighted that the use of IFC standard template partially hinders the semantic-enrichment capabilities of these models since it is not suited to the specificity, uniqueness, and context-dependence of a heritage artefact. In fact, some of the information necessary for the representation of heritage buildings cannot directly be formalized through IFC standards, while other has to be forced in the IFC schema [23], resulting in a "semantic bottleneck" that affects quality and consistency of built heritage representation. For instance, considering an IfcWall entity, defined in the ISO 6707-1:1989 as "Vertical construction usually in masonry or in concrete which bounds or subdivides a construction works and fulfils a load bearing or retaining function", the relational property sets are conceived for describing the vertical spaces partition of new buildings - e.g. HasCoverings; HasProjections; HasOpening; ProvidesBoundaries - while the datatype properties take into account the geometric features of the object - e.g. Length; Width; Height; GrossSideArea - principally useful for design and quantification of a new building. If compared to the built heritage and conservation field, it is also of great importance to include in the representation the constructive features and the state of preservation features of an Artefact Entity in order to support the analysis and interpretation activities conducted by the involved specialists. In the case of a Wall Entity, it is indispensable to be able of describing its stratigraphy and other indicators useful to contextualise the object, understand its nature and possible changes over time.

\subsection{Semantic Web approaches for cultural heritage}

During the last ten years, some research has shown the potentialities of the introduction of Semantic Web technologies to improve representation and information management in building information processes [6]. Such approaches rely on the use of semantic networks, systems of concepts and logical relationships to decompose and make computable knowledge related to the AEC domain.

AEC research in this direction has mainly focused on the use of informative ontologies (both in RDF or OWL schema) for this scope, usually referring to the Industry Foundation Classes (IFC) representational template [44]. Recently, Semantic Web approaches have assumed a relevant role also in the cultural heritage information management, especially for representation of knowledge related to particular aspects such as heritage cataloguing or monuments damage [4] [47].

Since its introduction as ISO standard in 2006, the Conceptual Reference Model (CIDOC-CRM) [16] has become the main ontological reference structure for formalizing the knowledge related to museum assets. This core ontology allows representing, through a formal and highly specific language, the information on cultural heritage in relation to the concepts of space and time, thus supporting operations of reasoning and inference.

In this regard, the CIDOC allows expressing statements concerning different kinds of resources, such as physical objects or abstract concepts that are linked to temporal and spatial information or to actors and physical persons. The CIDOC-CRM also provides a wide range of formalized relationships between these resources, which allow formalization of even semantically complex concepts such as, for example, the activities run by a museum or specific events related to the creation of a specific asset or the birth of a certain individual. Since its introduction, the CIDOC-CRM had a large diffusion together with Functional Requirements for Bibliographic Records (FRBR) [29] which focussed on the representation of bibliographic aspects.

In addition, also professionally oriented ontologies have been developed such as the Information System for Monument Damage Description (MONDIS) [13], an ontological framework able to model and coordinate an automated reasoning behind the documentation of built heritage damages, their diagnosis and possible interventions.

Focusing on architectural heritage, it is appropriate to mention two experiences. The first one is the Architecture Metadata Object Schema (ARMOS) [2], a framework derived from the CIDOC-CRM template for cataloguing architectural heritage and in particular its formal aspects. The second one, named Semantic Technologies for Archaeological Resources (STAR) project [38], focuses on linking digital archive databases and vocabularies for documentation of archaeological sites. Eventually, as regards the earthen architecture investigation process, Mecca et al. [39] proposed a dedicated ontology for diagnostics workflow, in order to formalize sets of information guidelines.

Within the Italian institutional context, the Cultural-ON ontology [31] has been recently developed to support the identification of cultural sites and events promoted by the Italian Ministry.

On the one hand, those examples show the potentialities of applying ontology-based models to different fields of heritage representation, documentation and analysis, on the other hand, it can be easily observed that the interpretative component, which is necessary for architectural conservation, is not yet adequately addressed.

Other domain-specific ontologies have been progressively introduced to represent specific aspects of the heritage conservation process [20]. Within CIDOC-CRM, different models have been developed to widen the representation field. In particular two models may properly comply to the present research, CRMba and CRMsci, oriented to built archaeology and scientific investigation processes ([12]). Nevertheless, at present, a model addressing specifically to architectural heritage conservation process is still missing.

\section{Case study: the Oratory of San Saba}

In order to test and calibrate the model within a built heritage process, it was applied to the ongoing conservation project of the Oratory of San Saba (2013-2016), a small hypogeal church located in the historical centre of Rome. The project aims at the transmission to the future of the physical consistency of the building according to both aesthetic and historical issues [9].

In fact, this heritage architecture showed a high level of complexity in terms of both spatial, typological and constructive features, and of transformation along time, perfectly suited to a demonstration of 


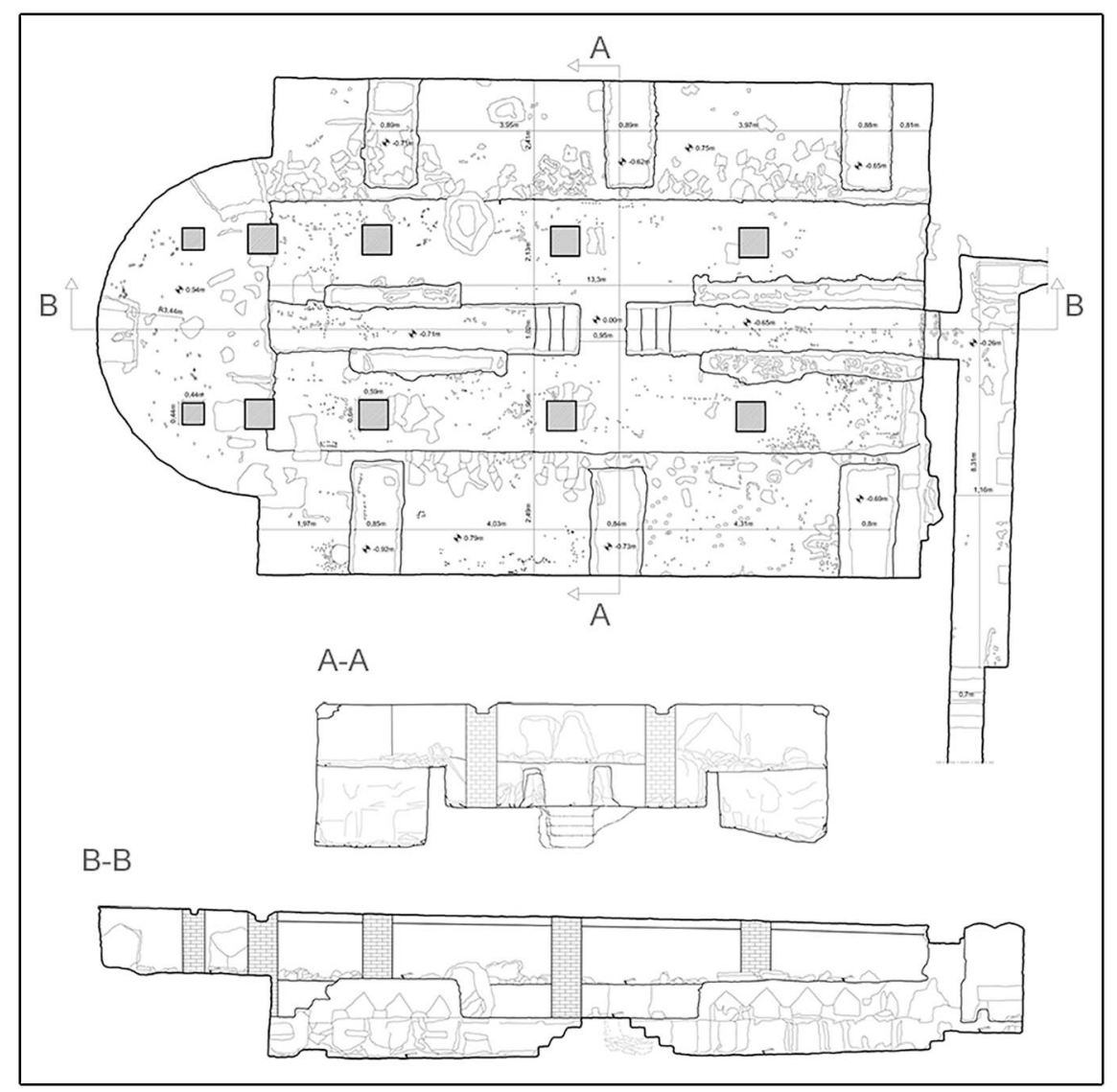

Fig. 1. Case Study of the Oratory of San Saba: plans and sections describing the current state of the artefact, investigated through traditional survey methodologies (drawings by $\mathrm{S}$. Cutarelli).

necessity and potentiality of a semantic-enriched BIM approach. The architectural heritage artefact, originally conceived as an oratory for the monastic community, was built on a previous roman domus (end of the 4th-century A.D.), was later transformed in a cemetery and later buried to act as the foundation for the medieval upper church, built in the eleventh century. Only at the beginning of the twentieth century, the Oratory was unearthed during the restoration works and made accessible. The Oratory has a basilical plan with a unique aula, that ends with an apse and is divided into three parts by some concrete pillars (covered by bricks) realised at the beginning of the 20th century in order to sustain the concrete floor (Fig. 1).

The masonry techniques are manifold, as the walls are the result of several transformations and covered with frescoes partially conserved. Underneath the walking level, a complex system of burial elements was realised in the 9th century. The tombs were organised in rows of three units divided by a corridor and built on two floors (Fig. 2).

Geometrical and architectural surveys were performed through both traditional methods and laser scanning, while other study activities have focused on the hermeneutical appraisal of the artefact. The first set of activities is directed at the full comprehension of the physical items and is carried on by multiple professionals. The second, generally performed by a conservation architect, is oriented to the comprehension of the elements that are not directly detectable on the building. It requires an interpretative effort focused on merging all information provided by the analytic process in a synthesis, which supports the critical assessment and gives direction to the conservation design.

In the investigation and conservation project of the Oratory of San Saba, a semantic-enriched BIM approach was considered as a consistent way to properly represent both physical components and the results of investigation activities and historical studies, providing a unified informative model to support decisions and actions.

\section{BIM Semantic-enrichment for architectural heritage}

\subsection{Methodology and conceptual structure of the model}

In the scope of the application of BIM principles and methods to built heritage processes, the present research relied on constructive research methodology to propose the integration of a BIM environment with a knowledge base created through information ontologies as a way to enhance quality and consistency of knowledge representation to fulfil architectural heritage requirements. In accordance to this methodology, after the clarification of the central problem to be solved - the semantic-enrichment of built heritage information models - and the analysis of the research efforts already performed in the same direction, an investigation of the semantic representation principles of the two approaches identified as potential part of more general resolutive template: BIM and Semantic Web based on information ontologies. Starting from this comparison and from the analysis of their representation templates (described in the Sections 4.2.1 and 4.2.2), the research has designed a conceptual structure of a model able to potentially formalize in a BIM model the knowledge produced and exchange in a built heritage documentation and conservation process. As later shown in Fig. 3, respective knowledge representation domains have been depicted and an inference engine integrated to provide semantic reasoning to the model. As required by the constructive research methodology, the connection between the different components of the model has been identified and a specific solution for the missing link between the BIM environment and the knowledge base has been conceived. As a derived result of this research, a prototype platform for this aspect has been developed and tested. Validation and assessment of the proposed model have been carried out by its application to different aspects and discipline-specific topics emerged from the real 


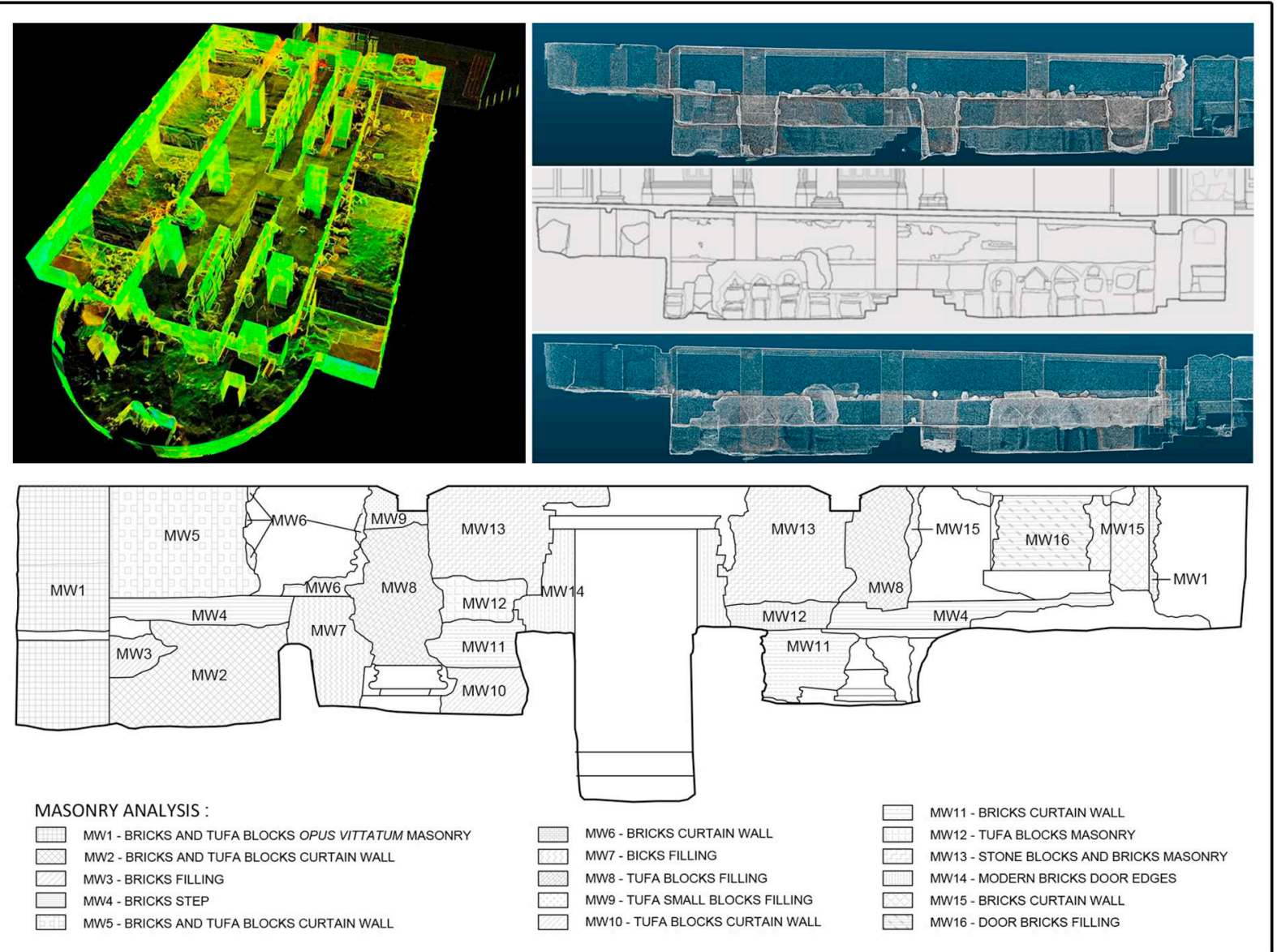

Fig. 2. 3D model of the Oratory of San Saba generated through laser scanning methodology (top) and northern wall masonry analysis (bottom). The masonry study shows the wall constructive complexity and its rich stratification (drawings by $\mathrm{S}$. Cutarelli).

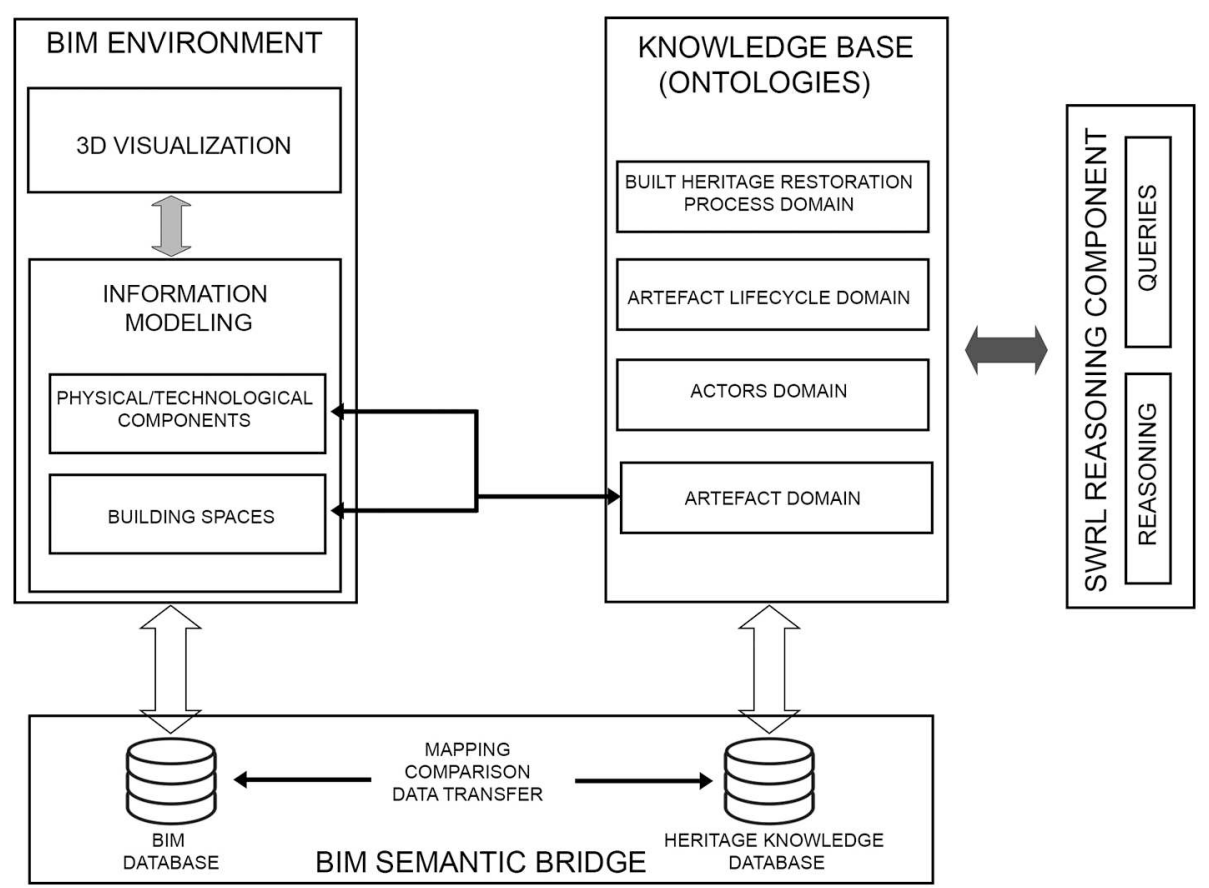

Fig. 3. The conceptual structure of the proposed model composed of the BIM environment, the Knowledge Base + the SWRL reasoning environment, and the BIM Semantic Bridge. 
conservation process of the described case study. The variety of the aspects considered allowed the assessment of the model efficacy as a whole as well as the single functioning of its components.

With reference to the knowledge base, by relying on similar approaches developed in the AEC field (and in particular on the Building Knowledge Modelling proposed by Carrara et al. [14], and by taking into account the different domain-specific ontologies developed in the cultural heritage, this research identifies four knowledge domains and their inner taxonomies, as well as proposing a set of relationships to connect knowledge entities both within the same domain or between different domains. Where it was possible, these taxonomies have embedded, adapted and extended previous ontologies developed in the built heritage sectors, and integrated them into a single and comprehensive knowledge base. Among the others, the CIDOC CRM [16] ontology translation and extension to architectural heritage scope were useful to formalize particularly aspects of building documentation such as its transformations. Where domain-specific ontologies were not available, new conceptual structures were developed and verified. For instance, the Built Heritage Conservation Process domain taxonomy was conceived by relying on the formalization of similar processes oriented to information acquisition, while the artefact domain structure partially relies on the well-known building decomposition in terms of spaces and building components. In any of the proposed domains, the research depicts some model principles rather than providing a static and rigid taxonomy; this allows to fully exploit the potential flexibility of ontology-based representations, allowing future users to customize, edit and enrich the knowledge base in order to fully adapt it to a specific use in a built heritage process.

Although information ontologies and relational databases - such as BIM databases - present conceptual differences [37], this research capitalizes two main analogies of the modelling methodologies of BIM and of Semantic Web: 1) the objects/relationships-oriented representation and 2) the abstract/concrete (often known as class/instance) specification.

In a BIM environment, buildings are decomposed in an organised set of entities and relationships, corresponding to the technological components of the artefact and to their relationships (such as the assembly rules or those referring to constructive and behavioural relationships). Similarly, semantic networks are structured as oriented networks of nodes and arcs, where nodes are concepts and arcs represent relationships between two concepts. This correspondence allows translating BIM structure into the ontologies framework, integrating its entities and relationships into a larger knowledge base able to organise different knowledge domains representation.

The second analogy refers to the abstraction/instantiation process that can be found in both BIM and ontologies environment: BIM relies on a family-type-instance schema that can be considered a simplification of the common class-subclass-instance structure, typical of ontology-based systems. This analogy can also be found at the properties level, since in both approaches entities are represented in terms of properties describing their main features, and values associated with those properties to define specific instances.

By comparing representation structures of BIM and of Semantic Web, we can recognise how BIM semantics can be embedded in a wider integrated formal model in which BIM entities, relationships, and rules are combined with other concepts and relationships, extending the represented domain(s) and raising the semantic level of representation.

Semantic-enrichment of heritage BIM also aims at including, in a single modelling environment, both direct and indirect knowledge related to the artefact. While BIM representation schema mainly focuses on the description of physical components of the building, the use of an ontology-based representation schema allows to explicitly represent concepts, abstract objects, contextual elements, and other cultural elements not physically showed by the artefact but still necessary for its comprehension [11]. This knowledge is not an external set of information to be used as a reference but is an essential part of the artefact architectural identity and, therefore, to be included in its informative model.

Computability of knowledge related to the artefact is another feature that can be reached through semantic-enriched BIM: the use of ontologies to extend BIM usual representation domain provides the possibility of operating on a variety of interconnected data, performing calculations, coherence checks and complex reasoning. This is a relevant shift for BIM support to conservation process since it provides a single modelling environment where the extensive representation of the artefact ensures coherence and consistency of interconnected information.

In the scope of architectural heritage, BIM semantic-enrichment also deals with the interpretation of information - and more generally of informative models - that is a relevant conservation aspect still overlooked by current BIM approaches to heritage. In new construction $\mathrm{BIM}$, in fact, the correct interpretation of building information is usually ensured by a common, implicit semantics that allows different actors to understand and manage the variety of different modelled entities and of all related data and information. This semantics, based on the component-driven decomposition of buildings, has actually shaped current BIM software that, in fact, provides as system families some classes of elements (i.e. walls, floors, etc.) and rigid assembly relationships among them. Therefore, interpretation of objects and information is quite simple for the different specialists involved. On the contrary, in built heritage field, variety, specificity and context-dependence of information requires interpretation of modelled information to be carefully guided. In this perspective, semantic networks allow providing information within its context of interpretation, enhancing actors' comprehension and, therefore, the awareness of their conservation decisions.

In this scope, we conceived a semantic-enriched building information model for the architectural heritage that is essentially made of four main components (Fig. 3):

1) A BIM environment;

2) A Knowledge base developed through an ontology-based system;

3) A Semantic Web Rule Language (SWRL) component to perform reasoning in the knowledge base;

4) A "BIM Semantic Bridge" that connects the BIM database and the knowledge base.

In the development of the prototypal application of the semanticenriched building information model for architectural heritage, some components have been implemented by relying on already available software (Autodesk Revit 2015 for the BIM environment and the ontology editor Protegé 3.5 for the Knowledge base and the reasoning component) while an ad hoc $\mathrm{C \#}$ application has been developed for the implementation of the BIM Semantic Bridge.

\subsection{The semantic-enriched building information model}

\subsubsection{The BIM environment for the architectural heritage artefact representation}

While in AEC field the Building Information Model is mainly a virtualization of the design enriched with constructive or management information such as materials, costs, etc., in architectural heritage its role is the representation of the artefact in terms of its physical components and their attributes elaborated by relying on information generated by the investigation process. Representation of an architectural heritage artefact in a BIM environment implies an act of discretization of the artefact, meant as its decomposition in terms of its physical and constructive components. This process, which depends both on the artefact nature and on the different specialists' assumptions, is carried out in the BIM environment by relying on the triple-layered representation template made of families, family types and instances.

Families are the more abstract level of the template and define 
classes of objects with similar meanings, functions, behaviours, and attributes. In the act of modelling the artefact, the conception and construction of families of components are one of the first steps that have to be carefully carried out and that can affect consistency and quality of the information stored in the model.

Family types are the result of the specification of some common features of a set of objects belonging to the same family. Their role is to classify and formalize different variations of the same category of objects depending on the variation of features and/or attributes. In fact, family types inherit all the attributes from the superordinate family and assign specific values to them in order to generate different configurations of the same category of elements. While families and the family types can be considered abstract layers in the modelling environment, the instances of elements are those that actually represent the artefact geometry, physicality, and configuration. In fact, the building information model of an artefact is generated by a process of specification that populates the model with virtual components that have unique values associated with the attributes inherited by the superordinate families/families types. Multiple similar elements can be generated by referring to the same family while operating on their parameters and attributes it is possible to control their variation and differences in terms of both features and behaviours. In the BIM environment, all the elements modelled and their parameters are formalized by ID into a relational database, divided in different tables accordingly to the superordinate family (Fig. 4).

The virtual model of the artefact generated by means of BIM approach embeds two main elements: geometry and semantics.

The first aspect is out of the scope of this research and, therefore, we chose to rely on already consolidated approaches and workflows. Independently from the geometry information being provided through traditional surveys or through advanced laser scanning techniques, each element geometry is controlled through family-dependent parameters that control attributes such as the thickness of walls, the height of columns, etc. Although if this approach necessarily implies a simplification of the accuracy of geometry representation, this level of adherence to reality was considered sufficient for the purpose of this research. Only when geometry was very particular and a high degree of accuracy was needed, we chose not to rely on geometry controlling through parameters but to directly import its elaboration from point clouds as collected during investigations. Without going much further, we can assume that, differently from the AEC where geometry is strictly generated through rigid parameters and allowed operations embedded in the family structure, architectural heritage requires a more flexible system for geometry representation that allows diversity in the input system, partially detaching geometry from family parameters.

In BIM environments, semantics is reduced to non-geometric attributes associated with the physical components of the artefact that can both store values (such as integers or strings) or point to other entities (usually by storing the ID of the target entity). Although this way of representing semantics is quite limited (especially if compared to the complexity of architectural heritage), the proposed system still partially rely on it solely for the part regarding features directly associated with the physical components. While in current BIM systems those attributes are just stored in the BIM environment, in the proposed system they are represented in a wider knowledge base (described in detail in Section 4.2.2) and then made accessible and editable in the BIM environment. If the representation in the knowledge base enhances coherence and consistency of information, the choice of allowing data access and editing in the BIM environment allows to perform usual BIM operations especially during management, design, and intervention as well as the use of collaboration tools and protocols.

To improve architectural heritage representation by means of BIM, a set of specific families and family types has been conceived and implemented. In addition to usual attributes referring to materials, dimensions, positions, some domain-specific attributes such as historic date, the state of decay, etc. have been introduced in the family templates, enriching BIM representation efficacy in the built heritage context.

In the application of the proposed model to the case study of the Oratory of San Saba, the building information model was used to represent and manage all the information directly associable to the artefact and to its components, including decay and stratification aspects. For instance, considering the traditional constructive analysis workflow, at first, a stratigraphic analysis and a masonry study were performed, providing information regarding all the actions that contributed to the actual configuration of the wall (stratigraphic units). This was followed by the study of the stratigraphic relations between the identified units, often represented by means of the Harris diagram. Further on the masonry study addressed the attention to the identification of constructive techniques and different typologies. Therefore, the model was articulated according to the requirements of an analytic description of the wall, ranging from stratigraphic unities and their

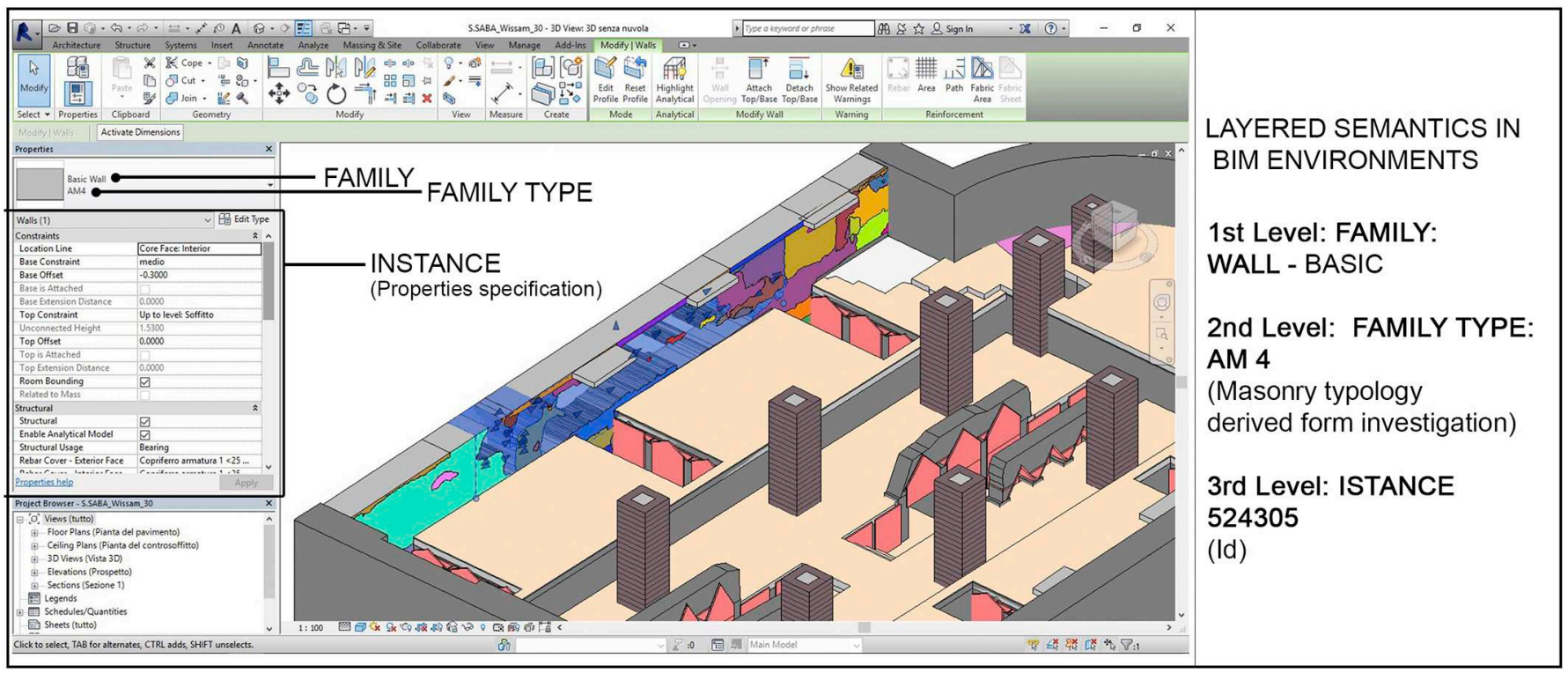

Fig. 4. The built heritage representation in the BIM environment: the Family-Type-Instance representation structure applied to a wall in the case study of the Oratory of San Saba. 


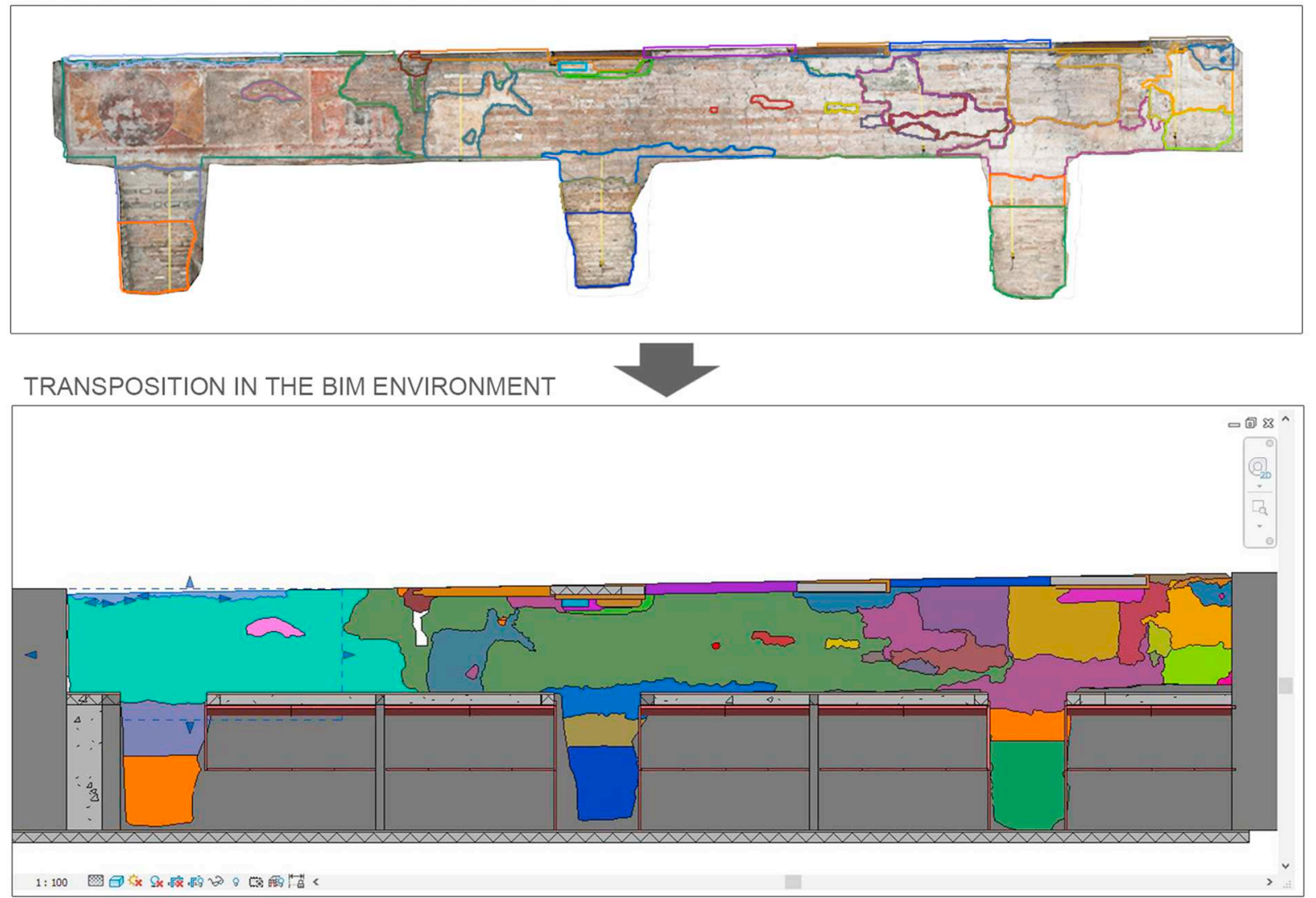

Fig. 5. The analysis of the northern wall of the Oratory of San Saba. The study of the wall transformations sharpens the knowledge of the multiple constructive components and gives direction to a consistent conservation project.

relations to the used materials. All instances identified within the ontological model have been represented within the building information model without any omission. This was possible thanks to the contemporary employment of the two instruments. To clarify this statement it is worthy to put the attention on the particular consistency of the northern wall. Besides stratigraphic units made of masonry, there are many reused elements such as tiles or column fragments that were included in the model. From a historical point of view, these elements have a double nature since their original functions have changed in time (i.e. a column base that is now part of a wall). In the BIM model, these elements were modelled as part of the wall, though the semanticenrichment allowed to specify their previous role in the building since function transformations cannot be disregarded in a conservation process (Fig. 5).

Currently, representation of a wall that pertains to cultural heritage, may hardly be achieved by the system BIM family "wall". As a matter of fact, a historical wall is usually the result of many transformations and, as a consequence, it can be made of different parts which are not simply different materials but masonry scraps remaining from the former walls as well as previous elements reused in the construction. These elements and the way they are connected (defined as stratigraphic relations) show very specific features whose uptake is preeminent as much information has laid on them through time [8]. In the case study of the Oratory of San Saba in Rome, to make it possible to represent, by means of BIM software, all vertical components and construction elements that constitute the walls, different "family types" were created. Each type of components (which simultaneously refers to a class in the ontology) such as masonry types, reused column bases, beams or curtain wall is represented by a family type. All types are then populated by individuals whose description is broadened by the ontology model.

\subsubsection{The knowledge base for heritage}

4.2.2.1. Knowledge formalization by means of ontologies. As defined by Gruber [25], an Ontology is "a specification of a representational vocabulary for a shared domain of discourse - definitions of classes, relations, functions, and other objects". Semantic Web technologies are currently used for the creation and utilisation of ontologies. Several standard ontology editors allow description and visualisation of the entities related to a knowledge domain through the explicit definition of classes, properties, relationships and instances. Moreover, the definitions of these representational primitives include information about their meaning and constraints and their logically consistent application.

The definition of a Class includes all the declarative aspects associated with the meaning of the represented entity, even in relation to the different domains of knowledge considered. This implies that all the represented knowledge is directly related to the entity of the specific ontology, thus establishing a relational structure between all the concepts, methods, and tools of interpretation, evaluation, and control of the entity and the considered disciplinary dominion. This formalization model is structured in a flexible, dynamic and rule-dependent way, so that, with reference to the context, and requirements, the meanings associated with the entities may be modified, or highlight knowledge base inconsistencies. A real item that fulfils the definition of a class is an Instance of this class.

All the descriptive and behavioural aspects related to the considered class - such as geometrical, physical and behavioural features - defined by specific values associated with the same attributes can be represented through Data Properties. The values associated with such properties can be computed by means of methods, algorithms and calculation procedures formalized and executed through inferential engines. Object Properties, instead, are used to define specific kind of 
relationships between two classes. An instance of an object property is a factual relation between two or more class instances.

To complete the structure of an ontology, a deductive layer consists of formalized rules able to verify and evaluate links and constraints between the entities considered in the ontology.

\subsubsection{The built heritage knowledge domains and their formalization} through ontologies. The application of Semantic Web technologies to the built heritage field currently focuses on specific activities and knowledge domains of the conservation process (such as recording or analysis of the monument conservation status), often neglecting the integrated and interdisciplinary nature of conservation process.

In this way, each step of the process - such as the preliminary stage of acquisition of knowledge, the value assessment, the diagnostics, the design, the intervention, and the maintenance phase - is addressed by isolating it from all other activities. In addition, by assigning an object to a class, it inherits all the properties of its representation model supporting the specialist to verify both the information already available and those that are still missing; therefore, operators can see which entities are not yet identified and, moving from their knowledge and experience, provide suggestions for their interpretation.

To represent the whole conservation process and the historical architecture to whom it is addressed to, this model defines four knowledge domains required to provide a comprehensive representation of the key aspects of a historical built environment: Artefact, Lifecycle, Built_Heritage_Conservation_Process and Actors. These domains of knowledge are formalized through semantic networks consisting of entities, properties, and relationships according to the previously described model. Specific resources of reasoning and inference allow the consistency check of the model of the ontology, in order to enhance the coherence of represented information and reduce discrepancies, inconsistencies, and errors in the formalized knowledge base (Fig. 6).

The construction of the domain-specific taxonomies was based on both deductive and inductive methodologies: the first was used to build an initial taxonomy classification, adherent with the consolidated knowledge in the built heritage field and to the existing cataloguing schemes [30], ensuring the consistency of data with the standards defined at a national level, thus guaranteeing the uniformity of the information, considered indispensable for a correct sharing of knowledge. The deductive approach, instead, relied on the typological and constructive description of the Oratory of San Saba and of the investigation process, to complete, correct and validate the initial taxonomy, including concepts, properties and rules even for undefined elements. To ensure the flexibility and adaptability of the knowledge structure, each class can be potentially enriched during the different conservation processes, with the scope of progressively extending the knowledge base. As a consequence, the proposed model should be considered as a conceptual framework to represent knowledge in different conservation processes and activities, while the encoded taxonomies are conceived to allow and support additional formalizations and in-depth analysis.

The Artefact domain includes all the entities related to the building configuration modelled by means of two main subclass-systems in terms of Spatial_Entities and Technological_Entities. Similarly to what proposed in the AEC field [15], the first includes the spaces delimited by physical elements or by other spaces, while the second includes the physical elements that define the constructive aspects of the artefact. Within the artefact domain, the classes belonging to these two systems can be structured through assembly relationships (formalized through object properties) in order to clarify the logical and technological composition of the building. For example, in the case study of Oratory of San Saba, the spatial, main instance of the Oratory is formalized as an assembly (a Whole off of an Aula, an Apse, several Funerary_Corridors, Isolated_Graves and Burial_Niches spatial instances (Fig. 7).

SpatialEntities are divided into four main subclasses: Spatial_Complex, Building_Unit, Spatial_Unit and Spatial_Component. The first one relates to a group of buildings considered as an organic whole such as, for example, the Chartreuse of Pavia. Building Unit represents a building with a specific function and architectural typology. Further on in the taxonomy, the class splits into many subclasses which refer to different functions (Civil, Religious, etc.) and typologies (Domus, Temple, Bath and so forth).

Spatial_Complex refers to an aggregate of buildings which represents

\begin{tabular}{|c|c|}
\hline \multicolumn{2}{|c|}{ BUILT HERITAGE KNOWLEDGE DOMAINS } \\
\hline $\begin{array}{l}\text { ARTEFACT } \\
\text { SPATIAL_ENTITY } \\
\text { Spatial_Complex' } \\
\text { Building_Unit } \\
\text { Spatial_Unit } \\
\text { Spatial_Component } \\
\text { TECHNOLOGICAL_ENTITY } \\
\text { Construction_Unit } \\
\text { Construction_Component } \\
\text { Construction_Element } \\
\text { Constructive_Material }\end{array}$ & $\begin{array}{l}\text { LIFECYCLE } \\
\text { SPACE } \\
\text { TIME } \\
\text { MATERIAL_OBJECT } \\
\text { IMMATERIAL_OBJECT } \\
\text { EVENT } \\
\text { Transformation } \\
\text { Modification } \\
\text { Beginning_Of_Existence } \\
\text { End_OO_Existence } \\
\end{array}$ \\
\hline $\begin{array}{l}\text { BUILT HERITAGE CONSERVATION } \\
\text { PROCESS } \\
\text { RESTORATION_PROCESS_ACTIVITY } \\
\text { RESOURCE } \\
\text { Investigation_Method } \\
\text { Investigation_Tool } \\
\text { Investigation_Sample } \\
\text { REFERENCE_INFORMATION_OBJECT } \\
\text { ATTRIBUTE ASSIGNMENT } \\
\text { APPELLATION_ASSIGNMENT }\end{array}$ & $\begin{array}{l}\text { ACTORS } \\
\text { ARCHITECT } \\
\quad \text { Materials Expert Architect } \\
\quad \ldots \\
\text { ENGINEER } \\
\text { PHYSICIAN } \\
\text { CHEMIST } \\
\text { BIOLOGIST } \\
\text { ARCHAEOLOGIST } \\
\ldots\end{array}$ \\
\hline
\end{tabular}

Fig. 6. The domains of the built heritage knowledge base framework (with their main classes) and their organisation in the ontology structure. 


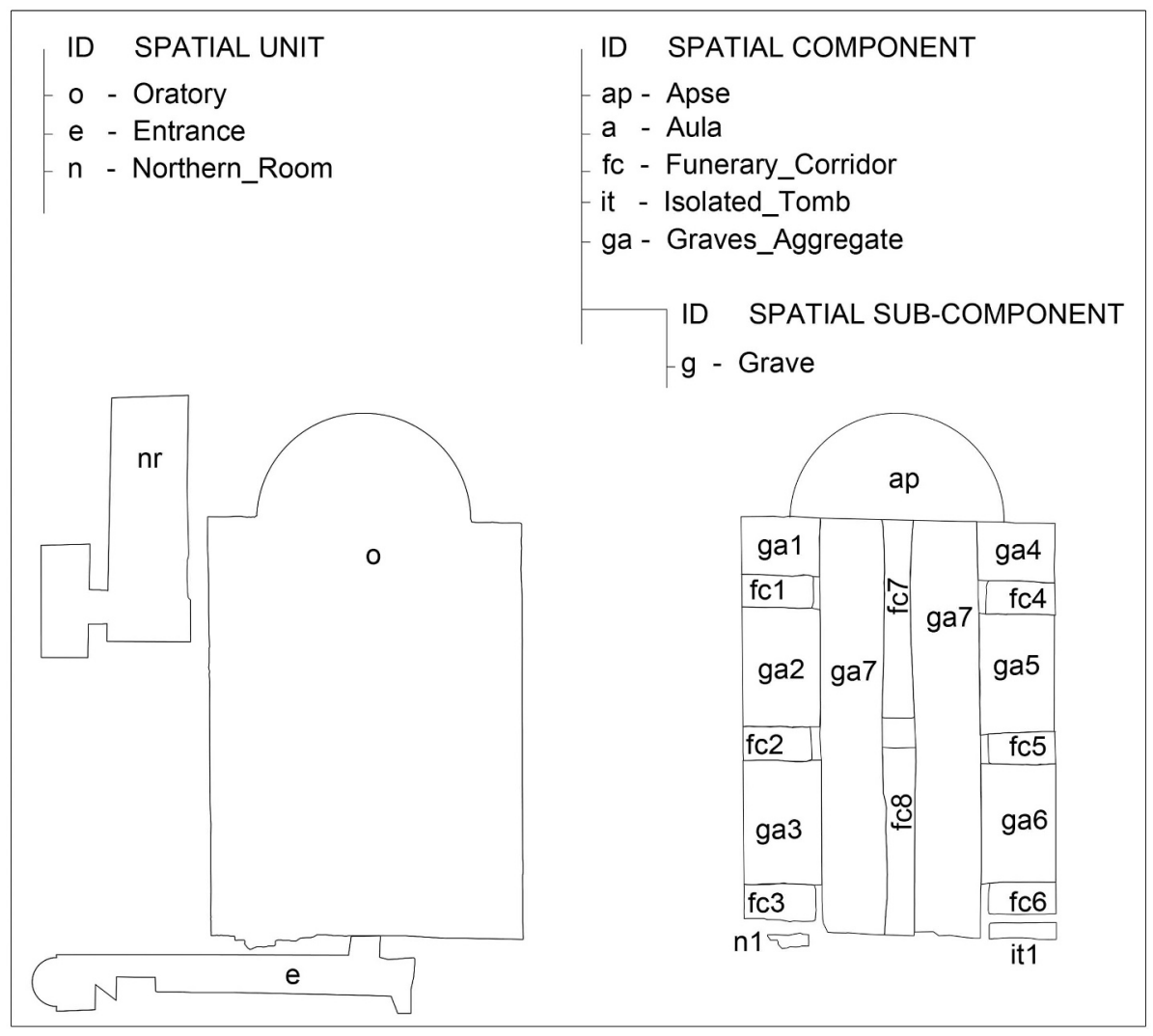

Fig. 7. Conceptual formalization of spaces in the Oratory of San Saba process. The classification of spatial units and spatial components has been developed upon spatial, typological and constructive studies. Within the Oratory, defined as a spatial unit, different components have been identified in order to describe the complex planimetric composition. an organic whole such as, for example, the Chartreuse of Pavia; Building Unit represents a building with a specific function and architectural typology. Further on in the taxonomy, the class splits into many subclasses which refer to different functions (Civil, Religious, etc.) and typologies (Domus, Temple, Bath etc.).

At a lower level, it is possible to achieve the representation of the building spatial structure. This is described through the Spatial_Unit, which are parts of the building with a proper architectural and functional identity and bound a continuous spatial ambit. For example, inside a building for the religious catholic cult, it is possible to recognise many spatial units such as the Church, the Chapel, the Belfry. In these classes, it is possible to formalize either social issues, patronage, specific function and use or properly constructive or planning items. At the lower representation level, Spatial_Component, describe the minimal spatial element that may not be further divided, i.e. the Nave, the Apse or the Transept.

In addition, the proposed ontology allows the complete description of the technological and constructive entities. Technological entities are articulated, according to their assembly complexity, in Construction_Unit, Construction_Component, Construction_Element and Constructive_Material (Fig. 8).

Complex parts, such as Covering, Floor, Elevation_Structure and Foundation are considered as construction unities. All types of communication structures either vertical or horizontal, i.e. Stair, Window or Door, are Communication, Horizontal or Elevation_Component, which are subclasses of Construction_Component. More in detail the horizontal elements may be structural, as a Concrete_Floor or a Stone_Vault or not structural as Fault_Vault or a wooden Counter_Floor. Elevation_Component class such as Column, Pillar, Wall, Partition. In this specific application of the proposed model to the case study of the Oratory of San Saba, the walls have been identified as front, back, and side in accordance with their topological relationships with the main aula. In more complex cases, irregular plants may be described through other classification approaches (i.e. through specification in terms of wall orientation or through specific codes).

The Construction_Element class is divided into two subclasses: complex and simple elements. A Masonry, composed of several layers, such as External or Internal_Wall_Layer and Nucleus, is considered an example of vertical construction elements. The Simple_Element class includes the basic components of a structure, such as Clay_Element, Mortar_Joint, Stone_Element.

The physical and functional transformations of the building, so the changes it has undergone over time, have been represented by a number of classes defined in the Lifecycle domain. Relying on the CIDOC knowledge structure [16] as the core ontology for the Lifecycle domain, this domain has been modelled by means of the explicit formalization of the history of the artefact in terms of Event $(s)$ (e.g. Transformation, Modification, etc.) connected, by means of specific object properties, with the concepts of Space and Time, as well as Material and Immaterial_Object(s). The latter represents all the intangible issues that are related either to the comprehension of the cultural and historical contexts or to the hermeneutical phase of the process, such as comparisons with other similar buildings or different interpretations proposed by other scholars. Their formalization deepens and enriches the knowledge of the artefact, which reveals itself as a system of relations belonging to a larger system than the one limited only to its physical and material components. In this way, the past can be represented as a series of events, placed in a spatial and temporal context, involving physical entities such as a Person or an Artefact but also conceptual entities such as the information collected (i.e. from a Bibliographic_Document) (Fig. 9).

Although the CIDOC ontology was conceived for formalization and documentation of museum assets, its generality and flexibility, in particular in the case of the description of history and modification of heritage artefacts, have made possible its adaptation to built heritage scope. In fact, many concepts and relationships from the CIDOC core ontology were already reusable in this knowledge area, while the ontology has been lately enriched with new elements more peculiar to the 


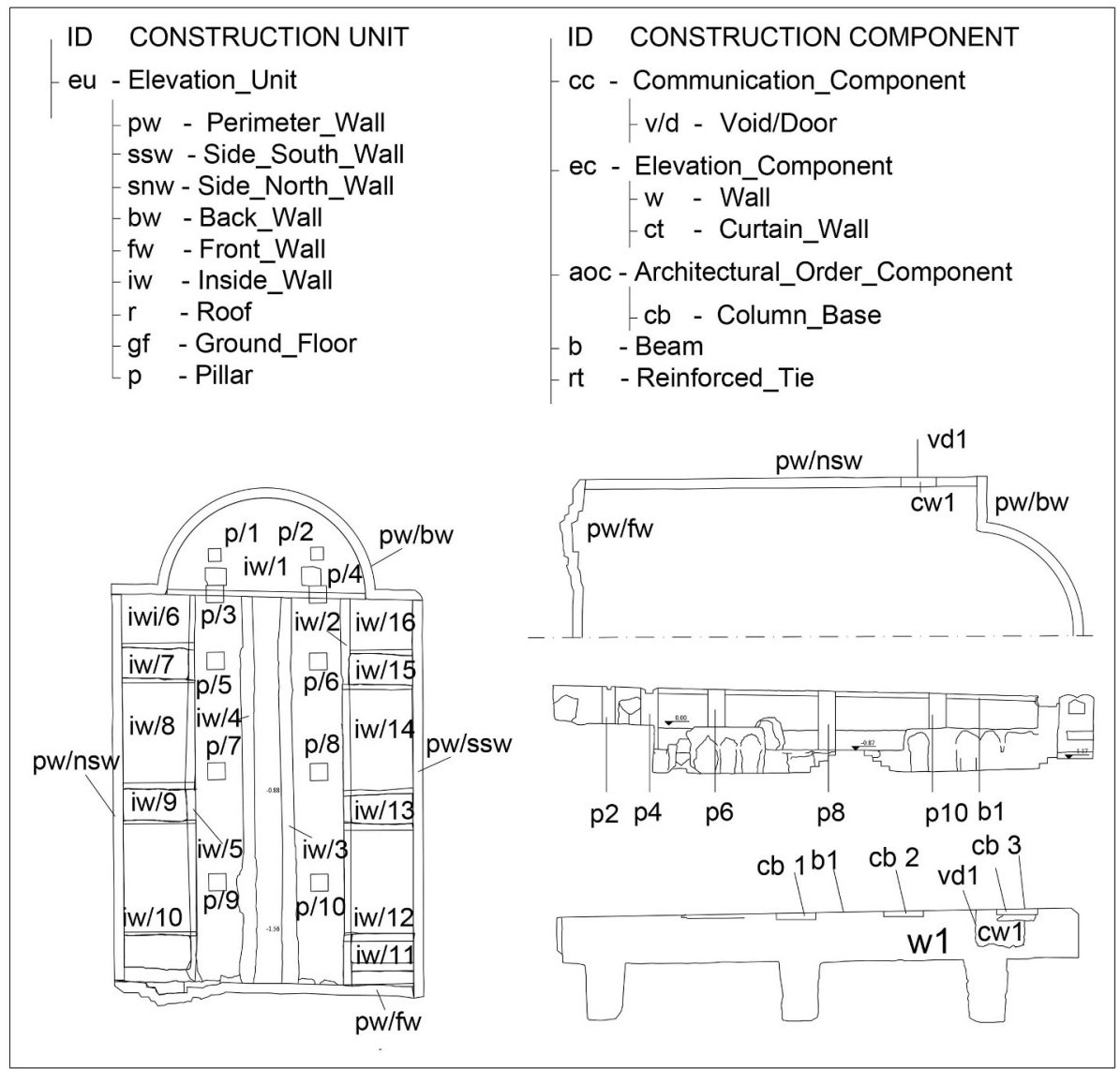

Fig. 8. Conceptual formalization of constructive elements of the Oratory of San Saba. Constructive units and constructive components have been classified through a critical assessment and assigned to general classes derived from a literature review of historic construction. Each elevation unit identified by the position and described through all the classes that represent the components that gather to its physical consistency. These classes may pertain to the modern building thesaurus as elevation components (wall, curtain wall); communication components (voids, doors etc.) or belong to specific ancient architecture lexicons, as elements from the architectural orders, historical reinforcements (reinforced ties, beams etc.). architectural heritage knowledge domain.

Referring to the case study, the initial roman artefact, formalized as an instance of a physical Artefact entity, is connected, through the object property was transformed by, to the related instance of the class Transformation which is an Event subclass. This event resulted in the later Church of St. Silvia, which is another instance of the Artefact domain.

The Event of Transformation of the Roman Aula to Church is also connected to the instance of the related Investigation Activity class that was carried out by a Person (in this case the historian $R$. Krautheimer) and which provided as output a specific Document.

The formalization of the Built_Heritage_Conservation_Process domain includes all the knowledge related to the activities of analysis, interpretation, and intervention involving the artefact. With the purpose of following the logical steps carried out by the operators during the investigation of a historical building, we chose to formalize the activities of investigation, analysis, and interpretation as subclasses of the Conservation_Process_Activity class. Resource $(s)$ entities have been used to represent tools, methods and samples used by operators during their activities; while the Reference Information Object(s) are used to represent the knowledge and the concepts used as input and provided as output during the various activities. Through the concepts of Attribute_Assignment and Appellation_Assignment, the survey, and analysis activities are linked to the interpretations and inferences produced by the actors, therefore modifying and/or increasing the knowledge related to the components of the artefact (Fig. 10).

In the case study of the Oratory of San Saba, in order to accurately represent the walls and provide an analysis of the stratigraphic composition of the masonries, the model embraces different domains and classes representing either physical entities and abstract concepts and information, interconnected in a semantic network. The wall instances and their parts are described through Construction_Component and Construction_Element classes and pertain to the Artefact domain (Fig. 8).
Since the results of an investigation activity of this kind are deeply affected by the investigation methodologies as well as the tools and resources used, specific classes have been conceived and formalized within the Built_Heritage_Conservation_Process (e.g. Stratigraphic_Unit, Wall_Sample, Direct_Investigation_Method, Direct_Measuring_Tool).

As a matter of fact, physical and abstract entities have been conceived in order to show, in some cases, common data properties. As an example, the Dating property is present either in the Stratigraphic_Unit class - portion of the wall whose features make it possible to refer to as a precise phase of building [8] - or in its physical components, namely the construction simple elements as Brick or Stone element or Joint that compose it. In this way is possible to compare information - even conflicting - coming from several investigations and different actors but related to the same entity.

To complete this brief analysis of the different formalized domains, the dedicated domain of the Actor is conceived to support knowledge management in built heritage processes. This Domain includes all subjects involved in the different stages of the process at different levels of detail and which interact with the entities of the other domains controlling their specific characteristics in relation to their needs. In addition to the collaboration enhancement, the correct formalization of knowledge helps each Actor to monitor the coherence and consistency of the ongoing investigations, interpretation and intervention activities.

\subsubsection{Reasoning and queries}

The expressive and descriptive potential of the proposed model not only resides in the semantic network formalization but also in the capability of deriving facts that are not directly expressed in the ontology.

As previously described, the semantic network consists of a set of axioms, which provide logical assertions about classes, individuals and properties as binary relations that link individuals to both data-type 


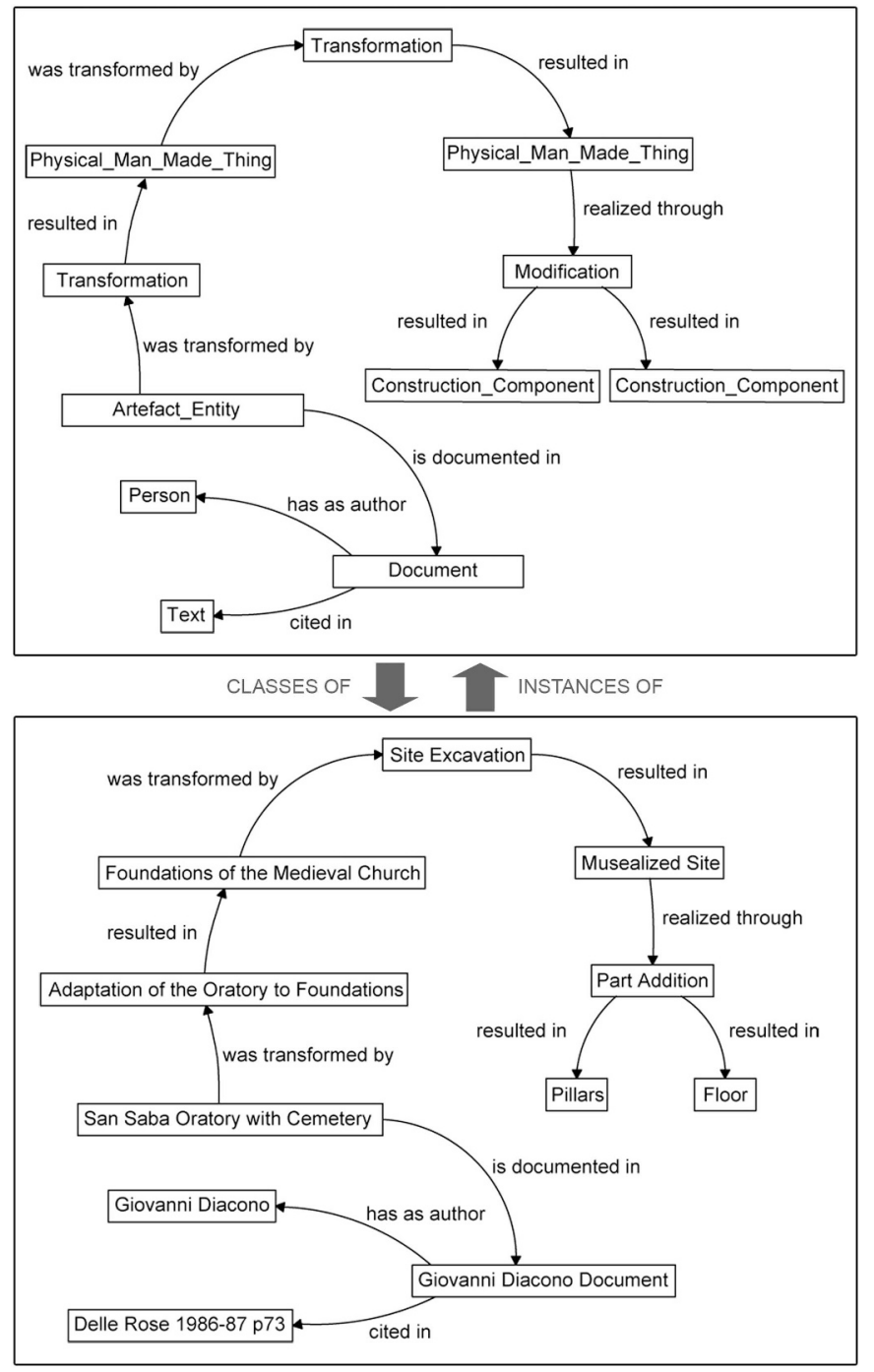

Fig. 9. Part of the ontology schema for the representation of the heritage building lifecycle, and its application to the historic transformations of the hypogeum of St. Saba to represent its physical and functional transformation as well as the related archival sources.

properties and other individuals. In a knowledge base accurately modelled, by using formalized reasoning and querying resources, we can infer other facts that are implicitly contained in the ontology. This sort of synapses provides a deductive level able to interrogate the knowledge base, verify the represented rules and infer new knowledge from that one already formalized. In this way, the system allows actors to use different and multiple levels of abstraction thus promoting true interoperability of concepts.

These rules, formalized in the proposed model by means of the Semantic Web Rule Language (SWRL), are composed of a set of propositions derived from the predicate logic [28]. Each proposition requires an implication between an antecedent (body) and consequent (head). Whenever the conditions specified in the antecedent hold, then the conditions specified in the consequent must also hold. Therefore, inferring rules can detect inconsistencies in the knowledge base, modify the concepts in terms of properties and relationships and change their meaning and thus the classes they belong to. This aspect is relevant since it is often not possible to define their nature and their features in a unique way. In addition, specific queries defined by the Semantic Query-Enhanced Web Rule Language (SQWRL) can operate in conjunction with SWRL and can thus be used to retrieve knowledge inferred by rules.

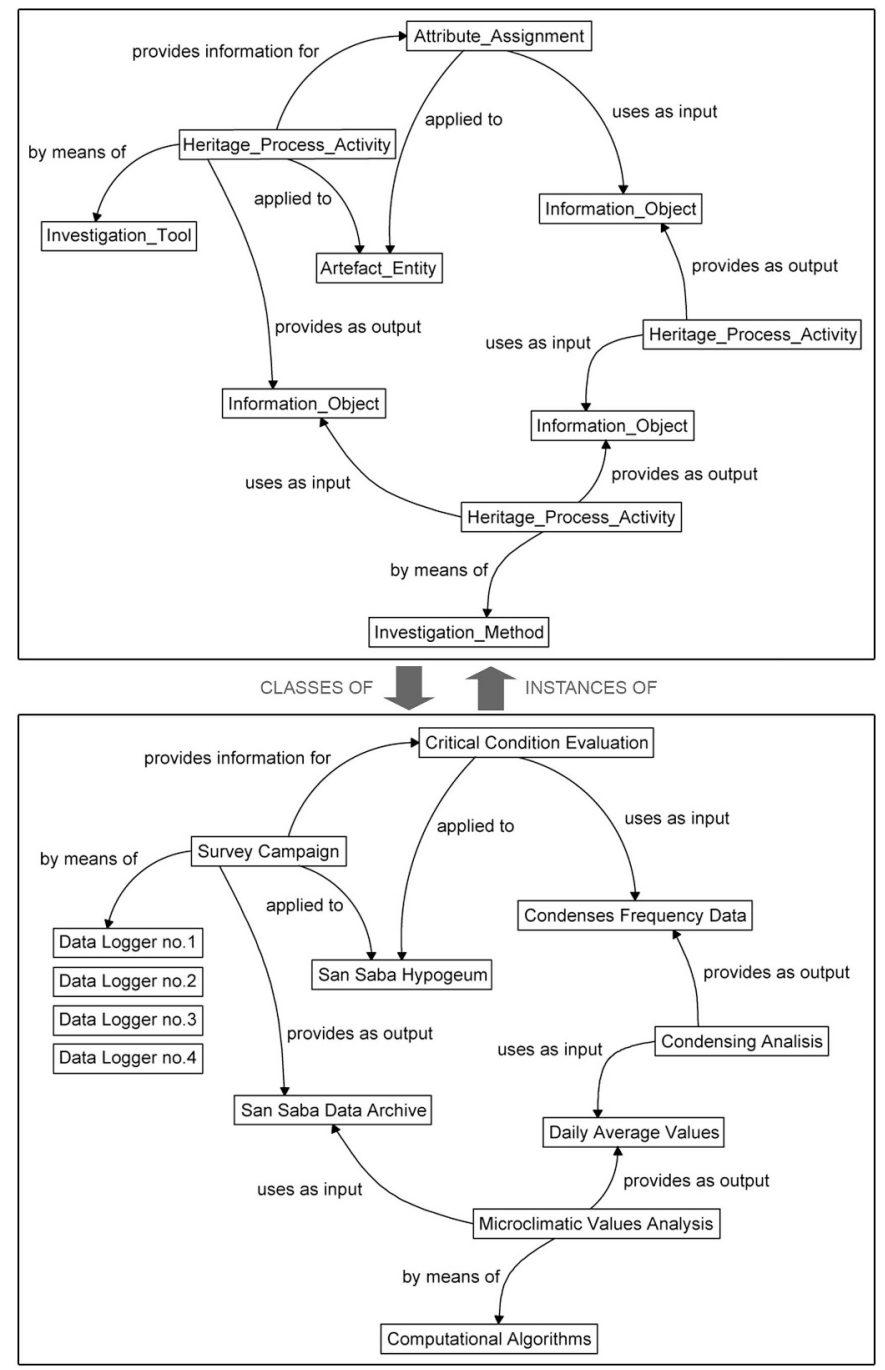

Fig. 10. Part of the ontology schema for the representation of investigation, analysis and interpretation activities within the built heritage conservation process knowledge.

The example shown below is an extract of the rules formalized through the SWRL language in order to verify the consistency of the information coming from a Harris Matrix analysis for identification and data assignment of different masonries belonging to the same wall [27]. Its main scope is to compare the laying sequence and the topological relationships that exist between the wall units with the dating that come from other investigation activities.

Wall_Unit(?a0) $\wedge$ Wall_Unit (?a1) $\wedge$ WallUnit InterpretedAge(?a0,? age1) ^ WallUnit InterpretedAge(?a1,? age2) ^ cover(?a0,? a1) ^ swrlb: greaterThanOrEqual(?age2,? age1) $\rightarrow$ temporal_relationship_incoherence (?a1, true) $\wedge$ temporal_relationship_incoherence(?a0, true).

More specifically this rule detects an information inconsistency if 1) there are two different individuals that belong to the Wall_Unit class with an InterpretedAge data-type property associated, and 2) between those individuals exists the cover relationship, and 3) the Wall_Unit covering the other one has an earlier dating.

Similarly, a set of rules has been created in order to verify inconsistencies between comparable information related to the same object but coming from different investigation activities and operators. The following example shows a list of rules formalized to retrieve and manage the dating associated with an artefact from both chronological and interpreted sources. 


\section{Rule 1}

Information_Object(?i0) $\wedge$ Age_Attribute_Assigment(?a1) $\wedge$ InformationObjInterpretedAge(?i0,? ageInterpreted1) $\wedge$ provides_information_for(?i0,? a1) $\rightarrow$ AttributeAssInterpretedAge(?a1,? ageInterpreted1).

Rule 2

Artifact_Entity(?w1) ^ Artifact_Entity(?w2) ^ differentFrom(?w1,? w2) $\wedge$ Age_Attribute_Assignment(?a1) $\wedge$ Age_Attribute_Assignment(?a2) $\wedge$ differentFrom(?a1,? a2) $\wedge$ applied_to(?a1,? w1) $\wedge$ applied_to(?a2,? w1) $\wedge$ AttributeAssInterpretedAge(?a1,? age1) $\wedge$ AttributeAssInterpretedAge(?a2,? age2) ^ swrlb:notEqual(?age1,? age2) $\rightarrow$ Interpreted_Age_Incoherence(?w1, true) $\wedge$ ErrorChecking (?w1, "The verification reported the presence of inconsistent interpreted dating attributed to the object").

Artifact_Entity(?w1) $\wedge$ Artifact_Entity(?w2) $\wedge$ differentFrom(?w1,? w2) $\wedge$ Age_Attribute_Assigment(?a1) $\wedge$ Age_Attribute_Assigment(?a2) $\wedge$ differentFrom(?a1,? a2) ^ applied_to(?a1,? w1) ^ applied_to(?a2,? w1) $\wedge$ AttributeAssInterpretedAge(?a1,? age1) $\wedge$ AttributeAssInterpretedAge $($ ?a2,? age2) ^ swrlb:equal(?age1,? age2) $\rightarrow$ Interpreted_Age_Incoherence (?w1, false).

Rule 3

Artifact_Entity(?w1) $\wedge$ Interpreted_Age_Incoherence(?w1, false) $\wedge$ Age_Attribute_Assignment(?a1) ^ AttributeAssInterpretedAge(?a1,? Age1) ^ applied_to(?a1,? w1) $\rightarrow$ ArtifactInterpretedAge(?w1,? Age1).

((...) (omissis)

Rule 4

Artifact_Entity $(? w 1) \wedge$ ArtifactCronologicalAge $(? w 1, ? a 1) \wedge$ ArtifactInterpretedAge $(? w 1, ? a 2) \wedge$ swrlb:notEqual(?a1,?a2) $\rightarrow$ ArtifactAgeIncoherence (?w1,true) $\wedge$ ErrorChecking (?w1, "The verification reported the presence of incoherence between chronological and interpreted dating attributed to the object").

Rule 5

Artifact_Entity(?w1) $\wedge$ ArtifactCronologicalAge(?w1,? a1) $\wedge$ ArtifactInterpretedAge(?w1,? a2) $\wedge$ swrlb:equal(?a1,? a2) $\rightarrow$ ArtifactAgeIncoherence(?w1, false) $\wedge$ ArtifactAge(?w1,? a1).

The check begins with a query (Rule1) for retrieving the age datatype from the Information_Object produced by an interpretation activity and then verifying and reporting if there are different Interpreted_Age values assigned to the same object (Rule 2). If the different Attribute_Assigment concerning the same object are congruent then the dating is assigned to the Interpreted_Age property of the instance (Rule 3). Similarly, the same actions are performed for the different chronological dates assigned to objects (omissis). To complete the reasoning process, rules 4 and 5 carry out the coherence verification between the possible interpreted and chronological dating assigned to the same.

In general, by combining, querying and inferring the knowledge collected during the conservation process, the involved specialists can be more aware of any interpretation inconsistencies and proposed solution implications, thus being able to choose the most suitable approach to follow for possible intervention projects.

\subsubsection{The BIM Semantic Bridge}

As discussed in Section 4.1, the proposed model relies on the integration of the usual BIM database with a knowledge base formalized through information ontologies. Since these two representation approaches are based on different modelling principles and protocols, it was necessary to conceive a specific platform - defined as BIM Semantic Bridge - able to translate the two modelling environments in a homogenous format and to create correspondences between the different entities represented in them. By accessing to the two modelling databases - one underlying a BIM environment, one derived from the knowledge base implemented through ontologies - the BIM Semantic Bridge performs and allows 4 main operations: 1) Reading and translation; 2) Entities mapping between the two databases in terms of classes, properties, instances, and values; 3 ) Comparison of the two information structures and 4) bidirectional update of the corresponding values.

Using the two databases as data sources, the BIM Semantic Bridge operates to reconstruct the taxonomies of classes of both sides, as well as assigned properties and derived instances. This operation homogenises the two representation allowing to generate correspondences between similar classes and data stored in both databases and perform comparison and data transfer. As described in Section 2.2, current BIM models are conceived on a two layers structure family-instances while ontology-based models can be extremely flexible in the depth of the taxonomy, accordingly to the specific knowledge domain to be represented. This difference is reflected in the structures of the underlying databases: BIM databases are organised as a set of connected tables, each representing an element family with instances formalized in rows and properties in columns. In this system, it is crucial the unique ID number progressively assigned to any new instance of the model, independently from its origin family, to avoid misidentification and data overlapping. In the ontologies side, instead, databases connected to the ontology are usually made of a single table, where differences between classes, properties, relationships and instances are controlled through "type" values, and identify with a unique string made of different substrings referring to the "mother class", the type, etc. In this way, the ontology can be continuously extended while its structure can be easily modified during the domain formalization. After the two databases have been imported and translated in the BIM Semantic Bridge, the system allows mapping the corresponding classes, properties, and instances between the BIM and the ontology sides. This mapping procedure is left to the user in order to take into account its requirements but, since the correspondences declarations are stored in a specific file, previous mapping schemes can be reused in similar design processes (Fig. 11).

Once the correspondences between classes, properties, and instances have been declared, the system allows performing both operations of checking and value transfer in both directions. The first task allows detecting, for any corresponding couple of entities, differences in terms of value for any corresponding property. In addition, this comparison allows detecting all the classes, properties, and instances that have not been mapped. The second operation, instead, transfers the value stored in an entity property to the corresponding one on the other side (from the BIM DB to the Ontology DB and vice-versa), updating the corresponding database and, therefore, the related model or ontology. These operations can be performed both for datatype properties and object properties (namely relational properties that have as a value type not a primitive - i.e. an integer or a string - but another instance of the model). Regarding the prototype implementation of the BIM Semantic Bridge, it has been developed in order to connect A BIM database underlying an Autodesk Revit model and formalized through the Autodesk DBLink application, and an OWL database generated through the ontology editor Protegé 3.5 [41] and an ODBC connection (Fig. 12).

Although the construction of both knowledge base and mapping file have to be performed manually, the system is conceived in order to potentially re-use knowledge structures, mapping correspondences and reasoning rules in similar heritage processes. In fact, in the case of similar artefacts that are subject to the same kind of investigation and conservation activities, the same knowledge base can be used, adapted and enriched. This means that a large part of the taxonomy and its mapping to the BIM entities is already available at the beginning of the heritage process, deeply reducing the work necessary for the preparation of the system.

During the development and application of the platform, some automapping methodologies have been tested, both by using similar names among the ontology and the BIM entities or by means of Uniclass correspondence. Although these applications reduce the amount of work, their use has to be carefully checked in order to avoid false correspondences or missing relationships between the two environments. 


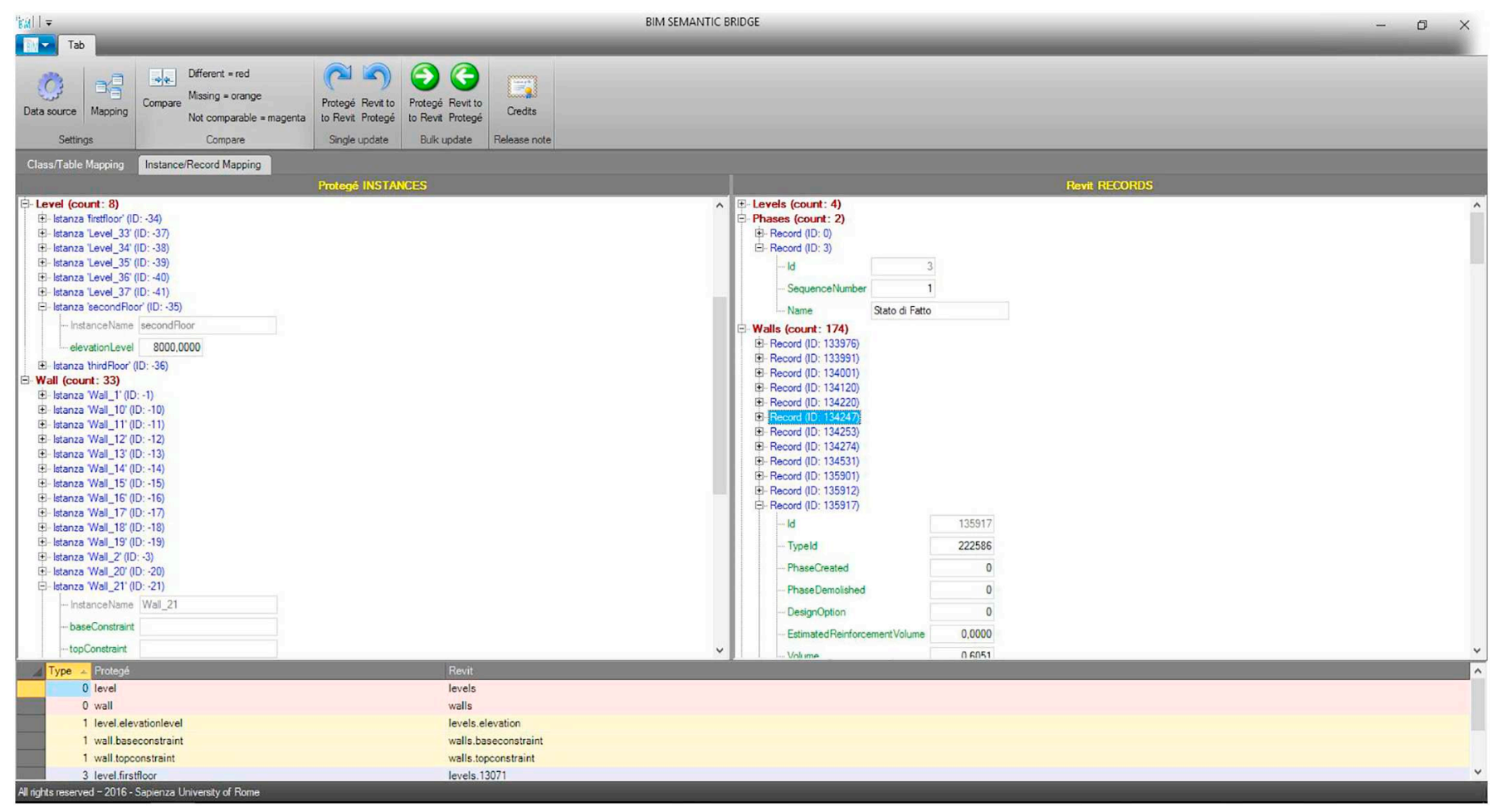

Fig. 11. The BIM Semantic Bridge platform: the Knowledge base (on the left) and the BIM database (on the right) linked through the mapping schema (in the lower part). The current version allows mapping, comparison and value transfer between the two environments.

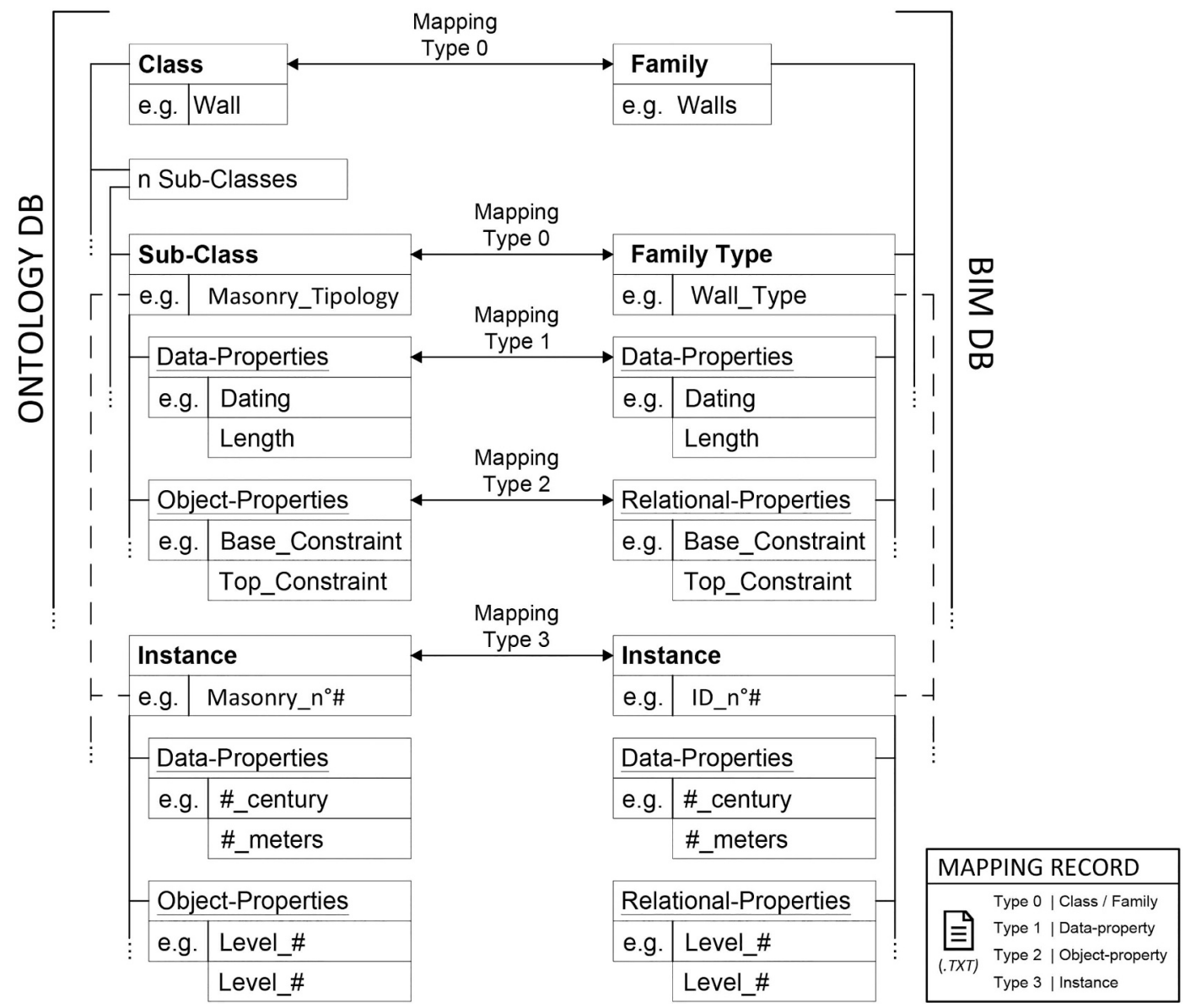

Fig. 12. The mapping schema BIM-Ontologies: The diagram shows conceptual taxonomy and mapping relationships between the different entities of the BIM environment and of the Ontology environment (family-class, family type-subclass, and properties). 


\section{Conclusions and future work}

The research hereby presented focuses on the development of a BIM semantic-enrichment approach that integrates BIM and a knowledge base developed through information ontologies as a way to enhance knowledge representation and management in built heritage processes. Since specifically tailored for built heritage information modelling, key features of the proposed model are the openness and capability of the representation framework to be adapted to the large scope of built heritage documentation and intervention. In a context that up to date has seen several discipline-specific extension of BIM methods to built heritage and the contemporary lack of their integration, this represents both a novelty and a reference point for both research and practice actions. Its scalability and adaptability, in fact, allow the incremental representation of knowledge during different built heritage processes, taking into account differences in the spectrums of artefact typologies and of heritage activities.

At the same time - and differently from previous research - the model supports the entire conservation process, merging the investigation phases with planning and management activities, allowing the continuous flow of information and ensuring its integration among the different disciplines involved.

The possibility of representing and integrating knowledge related to different domains and to different features of the heritage artefact also potentiates the crucial action critical approach, interpretation and assessment, that is one of the key specificities of cultural heritage that deeply affect the quality of the resulting decisions regarding the artefact.

At present, the main limitation to the system scalability is the representation range of the integrated BIM environment. For instance, the proposed knowledge base is potentially able to represent even larger systems of the artefact (i.e. a part of a historical city, or an ancient road), while BIM still suffers from the sole building perspective. Usability is also a key issue of the proposed system. Nevertheless, the complexity of the system is partially balanced by the potential re-use of representation templates in the field of heritage. In fact, different knowledge base structures, as well as the mapping correspondences with the BIM classes and the sets of reasoning rules, can be re-used, adapted and enriched for different heritage artefacts, while the single application of the proposed system could be unsustainable, its extensive application to similar cases could be both effective and convenient, especially for those architectural firms specifically dedicated to heritage conservation.

From the professional perspective, the predictive ability, the logical structuring of concepts of ontologies and their capability to act as translators between different information environment have proved to be extremely profitable regarding risk assessment, and maintenance activities planning. Formalizing environmental and material description together with microclimate monitoring and decay analysis make it possible to manage the complex system of relations that occur between cultural heritage and its context.

In terms of implementation, the presented prototypal platform requires different improvements in order to be spread in built heritage practice and used in a professional perspective. In particular, automatic creation and mapping of entities on both the BIM environment and the knowledge base have been only partially investigated and it could effectively speed up operations during investigation phases. In addition, the necessity of a general integration interface, that allows architects and other specialists to operate without the necessity to skip from one software to the other, and automates repetitive actions such as data transfer or entities/properties mapping.

To conclude, upcoming applications of the proposed model to a vast plurality of case studies, diverse for typology, historical period and scale, will provide additional development directions, taking into account specificity and uniqueness of each built heritage process.

\section{Acknowledgements}

The present research has been developed within the Research Project of National Interest "BHIMM - Built heritage information modelling and management. A model for architectural conservation based on knowledge" (PRIN 2010-2011 - Principal Investigator Stefano Della Torre, Research Unit Coordinator Donatella Fiorani). The authors are grateful to Gianfranco Carrara and Antonio Fioravanti for their support and contribution to the research project.

The authors also want to acknowledge the work of Tommaso Asciolla in the conception and development of the BIM Semantic Bridge implementation, the work of Wissam Wahbeh for the development of the building information model of the Oratory of San Saba case study, and the historical study developed by Silvia Cutarelli.

\section{References}

[1] A. Adan, X. Xiong, B. Akinci, D. Huber, Automatic creation of semantically rich 3D building models from laser scanner data, Autom. Constr. 31 (2013) 325-337, https://doi.org/10.1016/j.autcon.2012.10.006.

[2] M. Agathos, S. Kapidakis, A Meta-Model Agreement for Architectural Heritage, Metadata and Semantics Research vol. 390, Springer, Thessaloniki, 2013, pp. 384-395, https://doi.org/10.1007/978-3-319-03437-9_37.

[3] Y. Arayici, Towards building information modelling for existing structures, Struct. Surv. 26 (3) (2008) 210-222, https://doi.org/10.1108/02630800810887108.

[4] M. Balsko, R. Cacciotti, Springer (Ed.), Monument Damage Ontology, Lecture Notes in Computer Sciences, vol. 7616, 2012, pp. 221-230, , https://doi.org/10.1007/ 978-3-642-34,234-9 22

[5] J. Beetz, I. Blumel, S. Dietze, B. Fetahui, U. Gadiraju, M. Hecher, ... R. Yu, DURAARK: enrichment and preservation of architectural knowledge, in: S. Munster, M. Pfarr-Harfst, M. Ioannides, P. Kuroczynsky, E. Quak (Eds.), How to manage data and knowledge related to interpretative digital 3D reconstructions of Cultural Heritage? Springer LNCS, 2016, , https://doi.org/10.1007/978-3-319-47,647-6_11.

[6] J. Beetz, J. Van Leeuwen, B. De Vries, An ontology web language notation of the industry foundation classes, Conference on Information Technology in Construction, CIB-W78, 2005, pp. 193-198 Retrieved December 21, 2017, from https://pure.tue.nl/ws/files/2329360/Metis209539.pdf.

[7] M. Belsky, R. Sacks, I. Brilakis, Semantic enrichment for building information modelling, Comput. -Aided Civ. Infrastruct. Eng. 31 (4) (2016) 261-274, https:// doi.org/10.1111/mice.12128.

[8] A. Boato, L'archeologia in architettura: misurazioni, stratigrafie, datazioni, restauro [Archaeology in Architecture: Measurements, Stratigraphies, Dating, Restoration], Marsilio, Venezia, 978-88-317-9634-7, 2008.

[9] C. Brandi, Teoria del restauro [Theory of Restoration], Einaudi, Torino, $9788806155650,1963$.

[10] S. Bruno, M. De Fino, F. Fatiguso, Historic Building Information Modelling: performance assessment for diagnosis-aided information modelling and management, Autom. Constr. 86 (2018) 256-276, https://doi.org/10.1016/j.autcon.2017.11. 009.

[11] A. Bruschi, Introduzione alla storia dell'architettura: considerazioni sul metodo e sulla storia degli studi [Introduction to Architecture History: On Method and History of Studies], Mondadori, Milano, 9788861840454, 2009.

[12] G. Bruseker, N. Carbone, A. Guillelm, Cultural heritage data management: the role of formal ontology and CIDOC CRM, in: L.E. Vincent (Ed.), Heritage and Archaeology in the Digital Age, Quantitative Methods in the Humanities and Social Sciences, 2017, pp. 93-110, , https://doi.org/10.1007/978-3-319-65,370-9_6.

[13] R. Cacciotti, M. Blasko, J. Valach, A diagnostic ontological model for damages to historical constructions, J. Cult. Herit. (2015) 40-48, https://doi.org/10.1016/j. culher.2014.02.002.

[14] G. Carrara, A. Fioravanti, G. Loffreda, A. Trento, An Ontology-Based Knowledge Representation Model for Cross-Disciplinary Building Design: A General Template. Computation: The New Realm of Architectural Design -27th eCAADe Conference Proceedings, Instanbul, (2009), pp. 367-374 Retrieved December 22, 2017, from http://papers.cumincad.org/cgi-bin/works/Show?ecaade2009_161.

[15] G. Carrara, Y. Kalay, G. Novembri, Knowledge-based compsutational support for architectural design, Autom. Constr. 3 (2-3) (1994) 157-175, https://doi.org/10. 1016/0926-5805(94)90017-5.

[16] N. Crofts, M. Doerr, T. Gill, S. Stead, M. Stiff, Definition of the CIDOC conceptual reference model, ICOM/CIDOC Documentation Standards Group e CIDOC CRM Special Interest Group, 2010 Retrieved December 22, 2017, from http://www: cidoccrm.org/docs/cidoc_crm_version_5.0.4.pdf.

[17] M. Del Giudice, A. Osello, BIM for Cultural Heritage. ISPRS Annals of Photogrammetry, Remote Sensing and Spatial Information Sciences, Strasbourg, (2013), pp. 225-229, https://doi.org/10.5194/isprsarchives-XL-5-W2-225-2013.

[18] D. Di Mascio, P. Pauwels, R. De Meyer, Improving the Knowledge and Management of the Historical Built Environment with Bim and Ontologies: The Case Study of the Book Tower. Proceedings of the 13th International Conference on Construction Applications of Virtual Reality, London, (2013), pp. 427-436 Retrieved December 22, 2017, from http://hdl.handle.net/1854/LU-4227708.

[19] S. Dietze, J. Beetz, G. Katsimpras, R. Wessel, R. Berndt, Towards Preservation of 
Semantically Enriched Architectural Knowledge. 3rd International Workshop on Semantic Digital Archives (SDA) in Conjunction With the 17th Int. Conference on Theory and Practice of Digital Libraries (TPDL), Valetta, Malta, 2013 Retrieved December 22, 2017, from https://stefandietze.files.wordpress.com/2009/01/sda2013-duraark-cam-ready.pdf.

[20] M. Doerr, Ontologies for cultural heritage, in: S. Staab, R. Studer (Eds.), Handbook on Ontologies, Springer-Verlag, 2009, pp. 463-486, , https://doi.org/10.1007/9783-540-92,673-3_21.

[21] C. Dore, M. Murphy, Integration of Historic Building Information Modelling (HBIM) and 3D GIS for Recording and Managing Cultural Heritage Sites. Virtual Systems in the Information, VSMM 2012, 18th International Conference on Virtual Systems and Multimedia, Milan, (2012), pp. 369-376, https://doi.org/10.1109/VSMM. 2012.6365947.

[22] C. Eastman, Knowledge-based building information modelling, in: K. Kensek, D. Noble (Eds.), Building Information Modelling: BIM in Current and Future Practice, John Wiley \& Sons Inc., 978-1-118-76630-9, 2014.

[23] S. Fai, M. Sydor, Building Information Modelling and Documentation of Architectural Heritage: Between the 'typical' and the 'specific'. 2013 Digital Heritage International Congress (DigitalHeritage), Marseille, (2013), pp. 731-734, https://doi.org/10.1109/DigitalHeritage.2013.6743828.

[24] S. Garagnani, A.M. Manferdini, Parametric Accuracy: Building Information Modelling Process Applied to the Cultural Heritage Preservation. International Archives of the Photogrammetry, Remote Sensing and Spatial Information Sciences, Trento, (2013), pp. 87-92, https://doi.org/10.5194/isprsarchives-XL-5-W1-872013.

[25] T. Gruber, A translation approach to portable ontology specifications, Knowl. Acquis. 5 (2) (1993) 199-220, https://doi.org/10.1006/knac.1993.1008.

[27] E.C. Harris, Principles of Archaeological Stratigraphy, Elsevier, London, 9781483295855, 1989.

[28] I. Horrocks, P. Patel-Schneider, H. Boley, S. Tabet, B. Grosof, M. Dean, SWRL: A Semantic Web Rule Language Combining OWL and RuleML, Retrieved August 20, 2018, from W3C - World Wide Web Consortium: https://www.w3.org/Submission/ SWRL.

[29] IFLA Study Group, Functional Requirements for Bibliographic Records, K.G. Saur Verlag, Munich, 9783110962451, 1998.

[30] Italian Central Institute for Cataloguing and Documentation (ICCD), General Catalogue of Cultural Heritage, Retrieved August 22, 2018 from General Catalogue of Cultural Heritage, 2016. http://www.catalogo.beniculturali.it/.

[31] Italian Ministry of Cultural Heritage and Activities; Italian Institute of Cognitive Sciences and Technologies, Cultural-ON (Cultural ONtology): Cultural Institute/Site and Cultural Event Ontology, Retrieved August 22, 2018, from Dati.beniculturali.it, 2016. http://dati.beniculturali.it/cultural-ON/ENG.html.

[32] Y. Jeong, Mediating Semantics for Multidisciplinary Collaborative Design, ProQuest Dissertation Publishing, Berkeley, 2008 Retrieved December 22, 2017, from https://search.proquest.com/openview/c6ac1ff20a33f6bc73ec9c19941966f5/1? pq-origsite $=$ gscholar\&cbl $=18750 \&$ diss $=y$.

[33] Y.E. Kalay, Enhancing multi-disciplinary collaboration through semantically rich representation, Autom. Constr. 10 (6) (2001) 741-755, https://doi.org/10.1016/ S0926-5805(00)00091-1.

[34] M. Koolen, J. Kamps, V. Keijzer, Information retrieval in cultural heritage, Interdiscip. Sci. Rev. 34 (2009) 268-284, https://doi.org/10.1179/ $174327909 X 441153$

[35] R. Letellier, W. Schmid, F. LeBlanc, Recording, Documentation, and Information Management for the Conservation of Heritage Places: Guiding Principles. Los Angeles: Getty Conservation Institute, (2007) 978-0-89236-925-6.

[36] C. Lima, B. Fies, B. Zarli, M. Bourdeau, M. Wetherill, Y. Rezgui, Towards an IFC- enabled ontology for the building and construction industry: the e-COGNOS approach, in: Y. Rezgui, B. Ingiride, G. Aouad (Eds.), Towards a European Knowledge Economy in the Construction and Related Sectors, Proc. of the eSM@RT 2002 Conference, Salford, 2002, pp. 254-264 Retrieved December 22, 2017, from http:// orca.cf.ac.uk/id/eprint/34477.

[37] C. Martinez-Cruz, I.J. Blanco, M.A. Vila, Ontologies versus relational databases: are they so different? A comparison, Artif. Intell. Rev. 38 (2012) 281-290, https://doi. org/10.1007/s10462-011-9251-9.

[38] K. May, C. Binding, D. Tudhope, A STAR is Born: Some Emerging Semantic Technologies for Archaeological Resources. On the Road to Reconstructing the Past. Computer Applications and Quantitative Methods in Archaeology (CAA), Archaeolingua, Budapest, 2011, pp. 111-116 Retrieved December 22, 2017, from http://proceedings.caaconference.org/paper/cd53_may_et_al_caa2008/.

[39] S. Mecca, C. Cirinnà, M. Masera, A Semantic Web Portal for Supporting Knowledge Contribution, Sharing, and Management in the Earthen Architectural Heritage Domain. Terra 2008: The 10th International Conference on the Study and Conservation of Earthen Architectural Heritage, Getty Institute, 2008, pp. 114-119 Retrieved December 22, 2017, from http://craterre.org/diffusion:ouvragestelechargeables/view/id/31889df9c3ba804068290047b242185a.

[40] M. Murphy, E. McGovern, S. Pavia, Historic building information modelling (HBIM), Struct. Surv. 27 (4) (2009) 311-327, https://doi.org/10.1108/ 02630800910985108.

[41] M.A. Musen, The Protégé project: a look back and a look forward, AI Matters 1 (4) (2015) 4-12, https://doi.org/10.1145/2757001.2757003.

[42] D. Oreni, R. Brumana, S. Della Torre, F. Banfi, L. Barazzetti, M. Previtali, Survey Turned Into HBIM: The Restoration and the Work Involved Concerning the Basilica di Collemaggio After the Earthquake (L'Aquila). ISPRS Annals of Photogrammetry, Remote Sensing and Spatial Information Sciences, (2014), pp. 267-273, https://doi. org/10.5194/isprsannals-II-5-267-2014.

[43] P. Pauwels, R. Bod, D. Di Mascio, R. De Meyer, Integrating Building Information Modelling and Semantic Web Technologies for the Management of Built Heritage Information. Digital Heritage International Congress, IEEE, Marseille, 2013, pp. 481-488 Retrieved December 22, 2017, from http://hdl.handle.net/1969.1 151454.

[44] P. Pauwels, E.J. Corry, D. Coakley, J. O'Donnell, M. Keane, The Role of Linked Data and Semantic Web in Building Operation. Proceedings of the 13th Annual International Conference for Enhanced Building Operations. Montréal, Retrieved December 22, 2017, from, 2013. http://hdl.handle.net/1854/LU-434809.

[45] P. Pauwels, R. Verstraeten, R. De Meyer, J. Van Campenhout, Architectural Information Modelling for Virtual Heritage Application. Digital Heritage Proceedings of the 14th, Archaeolingua, Cyprus, 2008, pp. 18-23, https://doi.org/ 10.1109/DigitalHeritage.2013.6743787.

[46] H. Penttilä, M. Rajala, S. Freese, Building Information Modelling of Modern Historic Buildings Predicting the Future - 25th eCAADe Conference Proceedings, Delft, (2007), pp. 607-613 Retrieved December 22, 2017, from http://papers.cumincad. org/data/works/att/ecaade2007_124.content.pdf.

[47] R. Quattrini, C. Pierdicca, C. Morbidoni, Knowledge-based data enrichment for HBIM: exploring high-quality models using the semantic-Web, J. Cult. Herit. 28 (2017) 129-139, https://doi.org/10.1016/j.culher.2017.05.004.

[48] The Charter of Krakow, Principles for Conservation and Restoration of Built Heritage (2000), Retrieved December 22, 2017, from, 2000. http://hdl.handle.net/ 1854/LU-128776.

[49] R. Volk, J. Stengel, F. Schultmann, Building Information Modelling (BIM) for ex isting buildings - Literature review and future needs, Autom. Constr. 38 (2014) 109-127, https://doi.org/10.1016/j.autcon.2013.10.023. 